\title{
Performance improvement of integrated thermal protection system using shaped-stabilized composite phase change material
}

\author{
Chenyu Cao ${ }^{\mathrm{a}, \mathrm{b}}$, Ruixing Wang ${ }^{\mathrm{a}, \mathrm{c}, *}$, Xiaodong Xing ${ }^{\mathrm{b}}$, Wenfeng Liu $^{\mathrm{a}, \mathrm{c}}$, Hongwei Song ${ }^{\mathrm{a}, \mathrm{c}}$ \\ Chenguang Huang a,c \\ ${ }^{a}$ Key Laboratory for Mechanics in Fluid Solid Coupling Systems, Institute of Mechanics, Chinese Academy of Sciences. Beijing 100190, China \\ ${ }^{\mathrm{b}}$ College of Mechanical and Electrical Engineering, Harbin Engineering University, Harbin 150001, China \\ ${ }^{\mathrm{c}}$ School of Engineering Science, University of Chinese Academy of Sciences, Beijing 100049, China
}

\section{A R T I C L E I N F O}

\section{Keywords:}

Corrugated core integrated thermal protection system

Thermal bridge phenomenon

Shaped-stabilized composite phase change

materials

Heat insulating property

Thermal-mechanical coupling analysis

Global optimization procedure

\begin{abstract}
A B S T R A C T
In this study, an innovative integrated thermal protection system (ITPS) concept that incorporates shaped-stabilized composite phase change material into corrugated core ITPS structure is proposed to strengthen the thermal protection performance. First, the heat transfer characteristics were investigated through both the heat insulation experiment and numerical transient heat transfer analysis. Then, the load bearing capacity is researched through the sequential thermal-mechanical coupling method. Finally, based on the established numerical analysis models, a global optimization procedure was established to verify the advantages of the proposed structure under the actual reentry conditions. Experimental and simulation results show agreement with each other on the thermal insulation ability. And a reduction of $18.46 \%$ in maximum bottom face sheet temperature was observed in the experiments when compared with the traditional ITPS. Moreover, the optimization results showed that the proposed ITPS achieved a reduction of $14.32 \%$ in weight and a decrease of $46.09 \%$ in thickness with respect to the traditional ITPS, which thereby contributes to the lightweight and high structural efficiency of the vehicle design.
\end{abstract}

\section{Introduction}

Hypersonic vehicles have to resist sever aerodynamic heating and pressure during the launch and re-entry processes. In order to ensure the safety of the hypersonic vehicles, the thermal protection systems (TPS) are widely acknowledged as one of the most key techniques to protect the hypersonic vehicles from overheating and maintain the aerodynamic shape without excessive deformation [1-3]. TPS is primarily designed for thermal insulation to maintain the underlying structures within the required temperature range, while the mechanical load-bearing capabilities are limited, and most loads are handled by the underlying load-carrying structure [4,5]. Thus, the traditional TPS would evidently result in low structural efficiency due to the singleness of function, followed by the increase in weight and launch cost of the hypersonic vehicle.

In order to promote the structural efficiency and further reduce the weight of TPS, many research work have focused on developing novel types of structurally and thermally integrated TPS (ITPS), including corrugated core ITPS $[6,7]$, ITPS with rigid insulation bars $[8,9]$, and ITPS incorporating zero expansion lattices [10]. Among them, the corrugated core ITPS is one of the most appropriate candidate ITPS structure due to its advantages in manufacture and filling properties. A typical corrugated core ITPS is illustrated in Fig. 1. It comprises the top face sheet (TFS), the bottom face sheet (BFS), and the web, which serves as the load-bearing structure. Meanwhile, the insulation material used to fill the corrugated core provides the thermal protection capability.

After the concept was firstly proposed by Bapanapalli [6] in 2006, the corrugated core ITPS has been intensively investigated in thermal and mechanical behavior analysis during the past decade by using theoretical analysis, numerical simulation, or experimental test. Martinez et al. [11-13] developed micromechanical methods to determine the local stresses in an ITPS subjected to mechanical and thermal loads by homogenizing the corrugated sandwich panel as an equivalent orthotropic plate. Gu et al. $[14,15]$ proposed a novel approximate analytical method for nonlinear transient heat transfer and a higher-order layerwise finite element model combined with homogenization techniques for bending and transient dynamic analysis of ITPS. Kai et al. [16-18] focused on the cellular core sandwich panels with the new constituent of ceramic matrix composite for lightweight ITPS, and the high-temperature mechanical behaviors are systematically obtained in

\footnotetext{
* Corresponding author.

E-mail address: wangruixing@imech.ac.cn (R. Wang).
} 


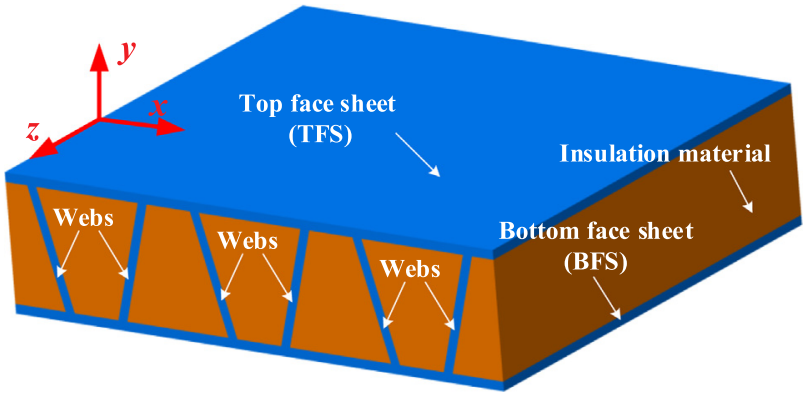

Fig. 1. Illustration of the typical corrugated core ITPS.

their recent works. Besides, many researchers have become interested in the optimization issue of corrugated core ITPS in recent years. Gogu et al. [19] obtained the optimal dimensions and the best materials for the spacecraft reentry ITPS system based on a corrugated core sandwich panel fulfilling thermal and structural constraints by the two-step optimization procedure. Villanueva1 et al. [20] explored the use of design space partitioning to dynamically locate all local optimal designs for ITPS by surrogate-based optimization method. Xie et al. [21] established an optimization procedure to design a corrugated core ITPS with the globally convergent method of moving asymptotes. The thermalstructural analysis and optimization of different ITPS configurations and insulating core options are respectively conducted by Meng et al. [22] and Jiang et al. [23]. Moreover, several optimization models have been investigated on multilayer corrugated core ITPS [24,25].

Although much development has been achieved in research so far, the engineering application of ITPS is still restricted by the heat bridge effect. As an important characteristic of a corrugated core ITPS, the web not only connects and integrates the TFS and the BFS, but also transfers the thermal and mechanical loads between the two sheets. Though the web enhances the structural stiffness, it simultaneously forms a thermal bridge, through which a large amount of heat is directly conducted from the TFS to the BFS. Clearly, the thermal bridge considerably reduces the thermal protection capacity of the corrugated sandwich structure. Thus, the filled insulation must be thickened to weaken the thermal short effect, which finally leads to low structural efficiency of ITPS. Many approaches have been developed to address the aforementioned problem. These approaches mainly include the hollow web design proposed by NASA Langley Research Center [26] and the hybrid truss core ITPS proposed by the Material Research \& Design team [27]. The core idea of these designs is to create a shortcut on the web to reduce the thermal path. Moreover, Yang et al. [28] proposed three improved structural concepts to tackle the thermal bridge problem and determined that the thermal short effect can be alleviated through web redesign. Later, they further established a topology optimization model of the web against the thermal short effect for ITPS, and the thermal short effect was effectively mitigated in the optimal design [29]. However, two major difficulties are encountered in applying the methods in engineering:

(1) All the design schemes are extremely complicated to be manufactured in large quantities.

(2) The hollow design in the web weakens the load-bearing performance.

Consequently, developing novel types of ITPS, which possesses favorable thermal insulating capacity on the premise of guaranteeing good manufacture and load-bearing properties, is still one of the most important issues that must be resolved.

Notably, almost all the existing methods focused on designing web configuration to alleviate the thermal short effect by increasing the thermal resistance. Thus, heat is prevented from entering the inner structure as much as possible. However, apart from thermal resistance, the heat transfer process is also highly dependent on the heat storage capacity [30]. Therefore, in theory, mitigating the effect of thermal short by increasing the heat storage capacity of ITPS is also a feasible approach, which has not been fully investigated in existing literature.

The phase change latent heat storage is widely acknowledged to be the most popular heat storage method, and the phase change materials (PCMs) have been widely applied in many fields of engineering recently due to the high heat thermal energy density and the nearly constant temperature during the thermal energy charge and discharge processes [31-33]. Consequently, to promote the heat storage capacity of ITPS, incorporating the appropriate PCM is a good choice. Actually, the European Space Agency (ESA) made the first attempt to utilize the PCM in the design of intelligent TPS, where the containers with PCMs were placed in the lower part of the metal frame to avoid the formation of hot spots inside the primary TPS structure [34]. Results showed that the PCM containers in the TPS can remarkably alleviate the hot spot effect caused by the thermal bridge and would result in mass savings of approximately $1.6 \mathrm{Kg} / \mathrm{m}^{2}$ by reducing $25 \%$ of tile height. However, this novel type of TPS has not obtained the anticipated attention because the complicated manufacturing process for the sealed container makes it difficult to be accomplished in engineering.

In this paper, a novel type of ITPS, namely, the phase change material based on corrugated core ITPS (PCM-ITPS), is proposed to mitigate the overheating caused by the thermal bridge in the traditional ITPS. In this design, the shaped-stabilized composite PCM, which is fabricated by absorbing the PCM into the porous structure, is utilized. Owing to the small size of the porous structure, the PCM is firmly locked in the pores even with the occurrence of solid-liquid phase change $[35,36]$. Through this structure, the composite PCM layer can be directly placed inside the empty room of the corrugated core, and the additional sealed container is eliminated. Thus, manufacturing of the PCM-ITPS is still easy, and the load-carrying properties can be maintained while the heat storage capacity increases. Therefore, the PCM-ITPS offers considerable potential in promoting the structural efficiency and performance of ITPS.

The objective of this work is to clearly reveal the thermal protection characteristics and load bearing performance of PCM-ITPS, and subsequently develop a design procedure to obtain the minimum mass of this novel structure for potential thermal protection applications. The rest of this paper is organized as follows. In Section 2, the innovative design scheme and geometrical features of PCM-ITPS is particularly described. In Section 3, the heat transfer characteristics of PCM-ITPS are explored by both heat insulation experiment and numerical simulation. In Section 4, the load bearing capacity of PCM-ITPS is investigated through the thermo-mechanical analysis. In Section 5, a design optimization procedure is developed to obtain the optimal structural configuration for PCM-ITPS under the actual reentry conditions. Finally, this paper is closed with some conclusion remarks in Section 6. The whole frame of the work can be illustrated in Fig. 2 .

\section{Novel design of PCM-ITPS for thermal protection enhancement}

The proposed design scheme of PCM-ITPS is displayed in Fig. 3. On one hand, the corrugated core sandwich structure including the TFS, the BFS and the webs, is retained to guarantee the load carrying capacity. On the other hand, the thermal insulation materials and the shaped-stabilized composite PCM are successively filled between the webs and face sheets to enhance the thermal protection capability. Note that, the following two points should be concerned here: (1) Considering that the temperature of the interior must be restricted less than $150{ }^{\circ} \mathrm{C}$ [34], the PCMs whose phase-transition temperature no more than $150^{\circ} \mathrm{C}$ should be adopted to make the best of the phase change latent heat storage. (2) In the design, the shaped stabilized composite PCM is layered below the insulating thermal material to prevent the PCM from decomposing under high temperature.

Moreover, as illustrated in Fig. 3, the geometry can be completely 


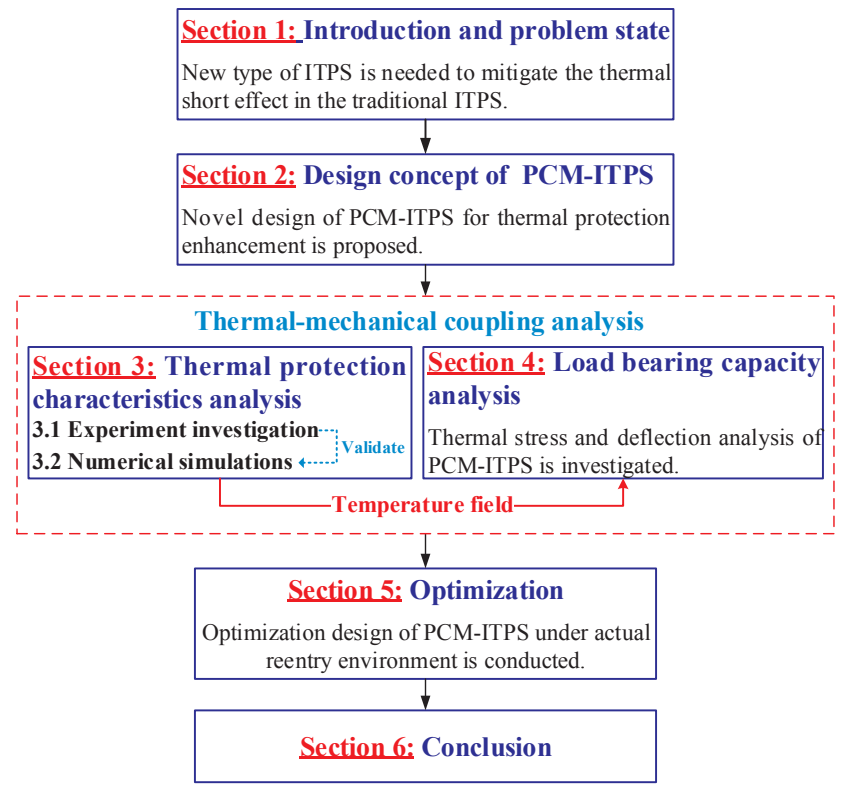

Fig. 2. Framework of the manuscript.

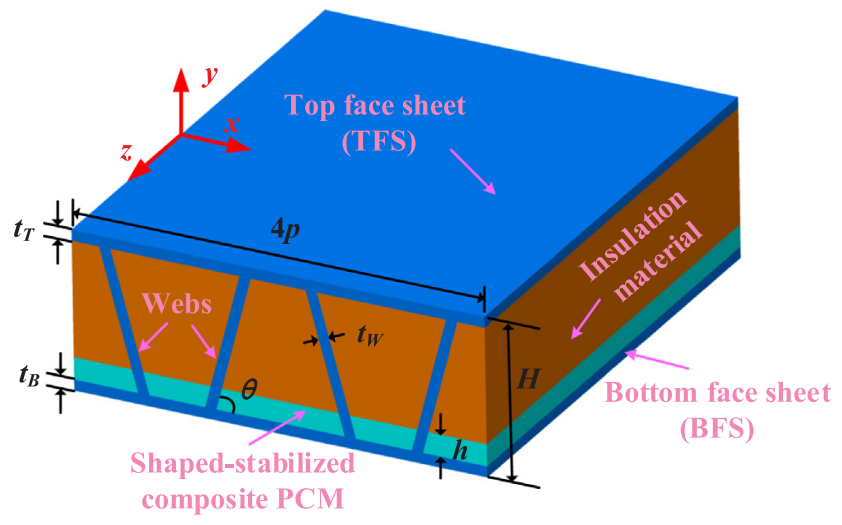

Fig. 3. Design scheme of PCM-ITPS.

described utilizing the following 7 geometric variables:

(1) The thickness of TFS, $t_{T}$;

(2) The thickness of BFS, $t_{B}$;

(3) The thickness of webs, $t_{W}$;

(4) The angle of the corrugations, $\theta$;

(5) The total height of PCM-ITPS, $H$;

(6) The height of the shaped-stabilized composite PCM, $h$;

(7) The length of a unit-cell of the PCM-ITPS, $2 p$.

\section{Thermal protection performance of PCM-ITPS}

The primary function of PCM-ITPS is to ensure that the vehicle temperature does not exceed the safe range. Therefore, the thermal insulation performance of PCM-ITPS should be first studied. In this section, both experimental investigation and numerical analysis were conducted to demonstrate the thermal insulation capacity of PCM-ITPS.

\subsection{Experiment investigation of the thermal protection performance}

\subsubsection{Preparation of shaped-stabilized composite PCM}

In this paper, SA-AC (a eutectic mixture of stearic acid and acetamide) was selected as the phase change material for the proper phase change temperature and favorable latent heat. Expanded graphite (EG) was selected as the matrix material to encapsulate the PCM as well as enhance the thermal conductivity [37]. Then, the composite PCM that comprises a mixture of EG and SA-AC was fabricated through simple blending and physical adsorption method [38]. The preparation process can be described as follows: (1) firstly, certain weight of SA-AC was introduced into flask which was heated to a predetermined temperature in oil bath; (2) secondly, certain weight of EG was added into flask and dispersed by continual stirring with glass rod until EG was saturated; (3) thirdly, all samples were cooled to room temperature and conserved for further characterization. Note that the mixing weight ratio of SA-AC and EG is 8:2 to process good stability according to Ref. [39].

After that, as shown in Fig. 4, the composite PCM was placed in a specified mould and dry pressed by material testing machine (GPTS2000M, Gopoint, China) to be shaped. Specially, in order to ensure the density of the stable composite PCM, both the mass and volume of the pressed PCM were precisely controlled during the pressing process by following operations: (1) the mass of PCM power was weighted by the electronic balance (HC2004, Hochoice, China), whose accuracy is $0.01 \mathrm{~g}$; (2) the PCM power was evenly placed in a stainless steel cubic mould which was specially made for the pressing process and (3) the volume of the pressed PCM was controlled by the pressing distance of the material testing machine. Therefore, the density of the pressed PCM can be guaranteed and calculated as

$\rho_{p}=\frac{M_{o}}{S_{M}\left(h_{o}-h_{p}\right)}$

where $\rho_{p}$ are the density of the pressed PCM; $M_{o}$ is the weight of PCM powder; $S_{m}$ is the surface area of the bottom of mould; $h_{o}$ is the original height from the pressing plate to the bottom of mould, $h_{p}$ is the pressing distance controlled by the material testing machine.

\subsubsection{Characterizations of shaped-stabilized composite PCM}

Typically, two kinds of composite PCM, namely PCM1 and PCM2, were prepared in this test. And the characterizations for the shaped stabilized composite PCM can be expounded as follows:
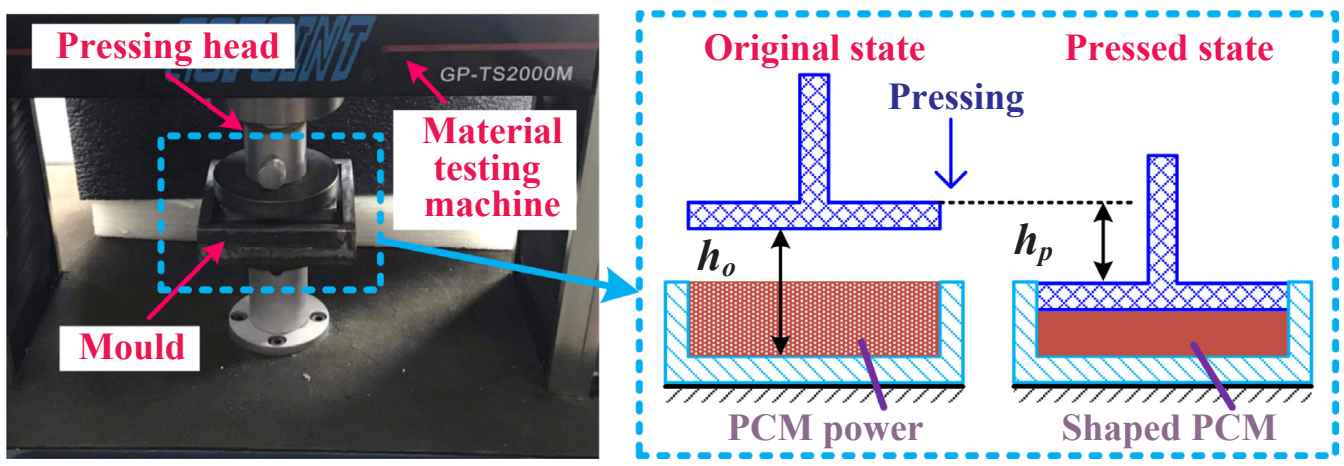

Fig. 4. Photograph of dry pressing process. 


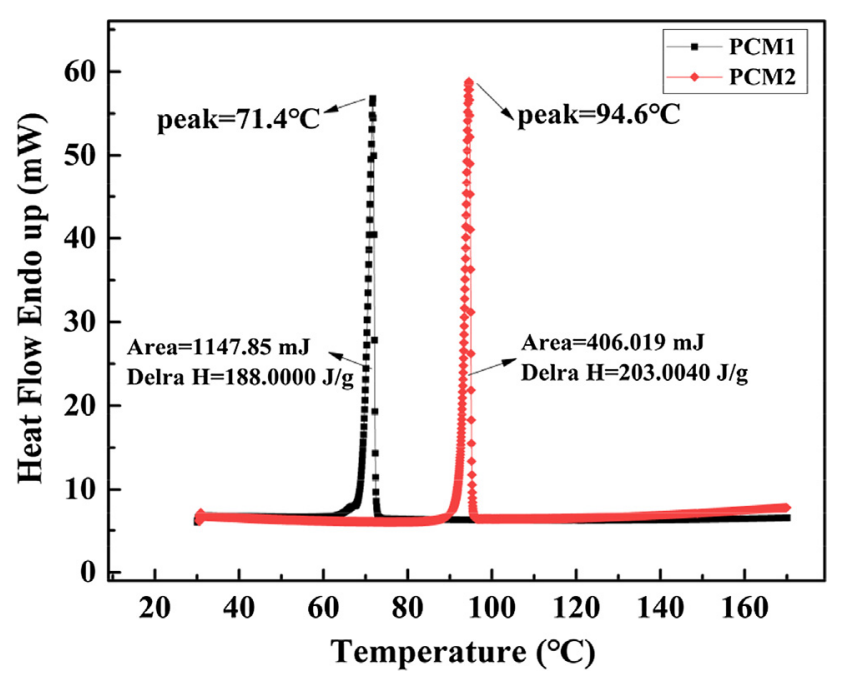

Fig. 5. DSC curves of PCM1 and PCM2 during the heating process.

(1) The phase change properties of the composite PCM, including phase change temperature, latent heat and specific heat were characterized by the Differential Scanning Calorimeter (Diamond-DSC-8500, American) at a heating rate of $5 \mathrm{~K} / \mathrm{min}$ in a pure nitrogen atmosphere. Considering that the heating process is the main issue for PCM-ITPS, the DSC curves of phase change behavior of PCM1 and PCM2 during the heating process are given in Fig. 5. Specially, as for the chemical stability, existing literatures have directly proved that no chemical reaction would occur between SA-AC and EG through the FT-IR spectroscopy [38]. Furthermore, the phenomenon observed in the DSC test that the phase change temperature of the composite PCMs did not change significantly from that of the pure PCM, can further demonstrate the viewpoint from a side [35].

(2) The thermogravimetric analysis test was characterized by thermogravimetric analysis systems (Diamond TG/DTA, PerkinElmer, American) at a heating rate of $10 \mathrm{~K} / \mathrm{min}$ and the results of TGA test are shown in Fig. 6. Based on the TGA curves, it was found that the prepared shaped-stabilized composite PCMs were stable and undecomposed below $175^{\circ} \mathrm{C}$, which means the prepared composite PCMs are suitable to be used in PCM-ITPS structures.

(3) The thermal conductivity was characterized by Physical Property Measurement System (PPMS-9, Quantum Design, American). The results shown that the thermal conductivity of PCM1 and PCM2 respectively increased to $1.15-1.26$ and $1.32-1.39$ due to the good

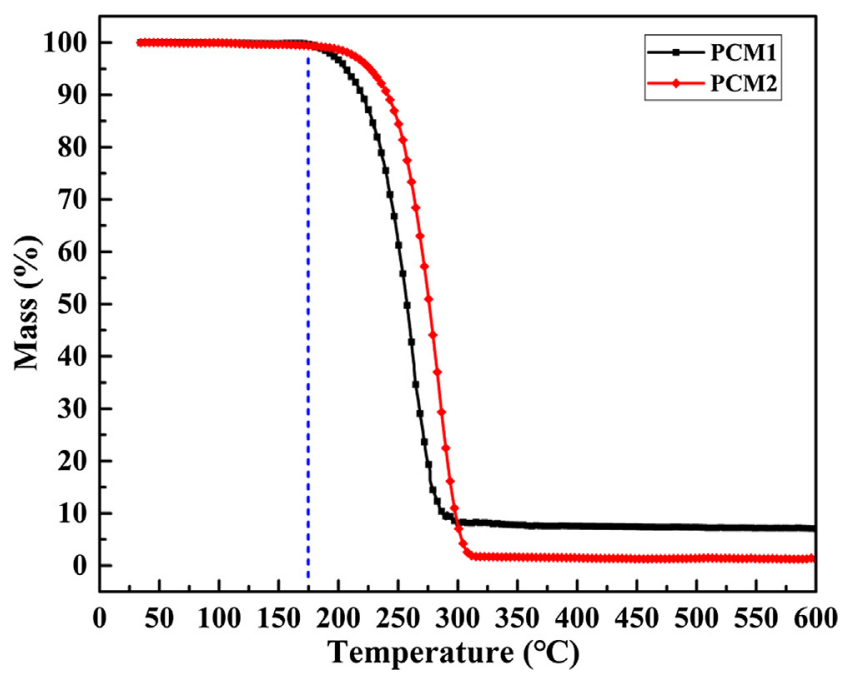

Fig. 6. TGA curves of PCM1 and PCM2. heat conduction property of EG.

(4) The external surface morphology and microstructure of composite PCMs was characterized by scanning electron microscope (SEM, SU8200, Japan). Fig. 7 displays the optical microscopy images of the composite PCM in different scales. As shown in Fig. 7(a), the graphite flakes appeared due to the dry pressing process. Meanwhile, the SA-AC was uniformly dispersed into graphite flakes and there is no obvious phase separation. Moreover, it was observed in Fig. 7(b) that the prepared composite PCM had a complex network of micron-sized structures, and the PCM was encapsulated by the micro-nano-scale structures. Since the pore size is small enough, the carbon structure is held together by strong covalent bonds, and the strong capillary action as well as the surface tension of the material can sufficiently adsorb PCM.

All in all, based on all the characterizations, the thermo-physical properties of the two kinds of shaped-stabilized composite PCMs can be summarized in Table 1.

\subsubsection{Preparation of PCM-ITPS}

S304 stainless steel obtained from Wuxi Zhongxinwei Stainless Steel Co., Ltd was selected as the load-bearing structural material and the temperature dependent physical properties can be found in [40] and listed in Table 2. The surface of the load-bearing structure is sandblasted in advance to ensure accurate temperature measurement with the infrared camera, which means the reflectivity of the observation surface should be kept small [41]. The treated test piece is shown in Fig. 8(a).

Then, the shaped-stabilized composite PCM layer used for filling in corrugated sandwich was prepared by cutting process and the prepared slab specimen is shown in Fig. 8(b). After that, the PCM layer was firstly filled into the bottom of the corrugated sandwich, and then, the heat insulating material was filled above the PCM layer. As shown in Fig. 8(c), the aerogel insulation fiber obtained from Shanghai Nanovix Thermal Insulation Co., Ltd was chosen as the heat insulation material and the physical properties is listed in Table 3. Specially, in this study, the traditional ITPS is additionally fabricated for comparison. Therefore, three different types of test pieces were prepared in this test, namely, the traditional ITPS, PCM-ITPS1 (corresponding to PCM1) and PCM-ITPS2 (corresponding to PCM2), which are respectively shown in Fig. 8(d)(e)(f).

\subsubsection{Experiment setup}

Schematic diagram of the whole experiment setup was illustrated in Fig. 9(a).

Firstly, the laser system (YLS-2000, Germany, Fig. 9(b)) was utilized as the heat source generator in the experiment for the following reasons: (1) the laser is able to simulate the aerodynamic heat flux in a certain area for the highly concentration of beam, which is suitable for the fabricated test pieces in this work; (2) the amplitude of heat flux can be easily controlled by the laser operation system and (3) compared with the traditional quartz lamp heating system, the experiment setup is simper because the heat shield system to prevent the non-directional heat generated by the quartz lamp from leaking is avoided.

Secondly, in order to fix the test piece and protect the measuring equipment behind the BFS, a fixture shown in Fig. 9(c) was designed. Besides, the Alumina $\left(\mathrm{Al}_{2} \mathrm{O}_{3}\right)$ insulation fiber was filled in the rest of the fixture to approximate the adiabatic boundary condition around the test piece.

Thirdly, the infrared thermal imager (FILR-T1050sc, American, Fig. 9(d)) was used to capture the temperature responses of the BFS, including the high resolution thermal images and the temperature data.

During the experiment process, the whole experiment setup was placed in an air-conditioned room to reduce the effect of temperature fluctuation and the test pieces were heated with heat source power density of $100 \mathrm{~kW} / \mathrm{m}^{2}$ for $120 \mathrm{~s}$ to preliminarily simulate the heat flux 

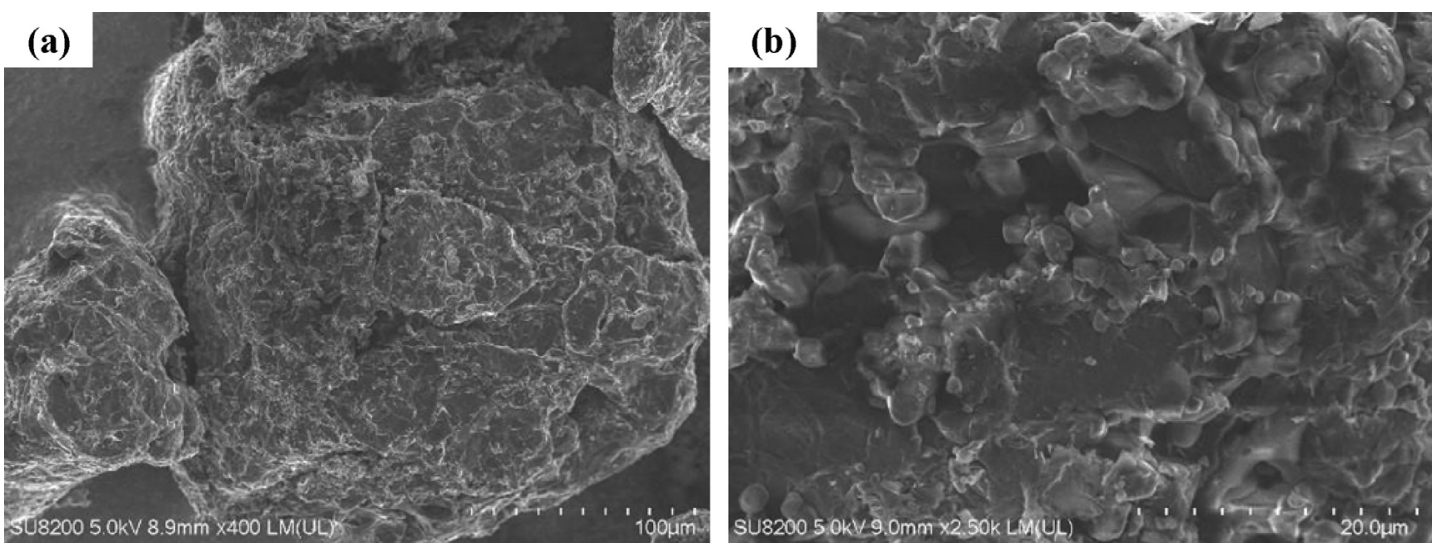

Fig. 7. SEM photographs of the composite PCM.

Table 1

Physical properties of the shaped-stabilized composite PCMs.

\begin{tabular}{|c|c|c|c|c|}
\hline Designation & PCM1 & & PCM2 & \\
\hline Density $\left(\mathrm{kg} \cdot \mathrm{m}^{-3}\right)$ & 870 & & 950 & \\
\hline Phase change temperature $\left({ }^{\circ} \mathrm{C}\right)$ & 71.4 & & 94.6 & \\
\hline Latent heat of phase change $\left(\mathrm{J} \cdot \mathrm{Kg}^{-1}\right)$ & 188,000 & & 203,000 & \\
\hline Thermal conductivity $\left(\mathrm{W} \cdot \mathrm{m}^{-1} \cdot{ }^{\circ} \mathrm{C}^{-1}\right)$ & 1.15 (solid) & 1.26 (liquid) & 1.32 (solid) & 1.39 (liquid) \\
\hline Specific heat capacity $\left(\mathrm{J} \cdot \mathrm{kg}^{-1} \cdot{ }^{\circ} \mathrm{C}^{-1}\right)$ & 950 (solid) & 1136 (liquid) & 1056 (solid) & 1210 (liquid) \\
\hline Thickness (m) & 0.005 & & 0.005 & \\
\hline
\end{tabular}

load that the hypersonic vehicle experiences during the reentry flight time. The laser beam was set to cover the surface of TFS by adjusting the distance between the laser head and fixture. Moreover, after the heating process, the test piece was left for an additional period of time to capture the maximum temperature of BFS.

\subsubsection{Experiment results and discussions}

The temperature distribution graphs in the specified observe region (shown in Fig. 10(a)) of different ITPS at 60 s, 120 s, 180 s, 240 s, 300 s are displayed in Fig. 10(b). During the test, a distinct high temperature zone around the locations of the webs was observed on the BFS for the traditional ITPS, which indicated that the thermal bridge caused by the webs severely weakens the heat insulation performance of ITPS. By contrast, for PCM-ITPS test pieces, namely, PCM-ITPS1 and PCM-ITPS2, it could be observed that the temperature obviously decreased and the thermal bridge phenomenon was greatly mitigated, which confirmed that the heat insulation property was effectively enhanced by incorporating the composite PCM. Additionally, the temperature distribution of PCM-ITPS was found to be more even than that of the traditional ITPS due to the high heat thermal energy density and thermal conductivity of the composite PCM layer. This appearance manifested that the nonuniformity of the temperature field caused by the thermal bridge phenomenon in traditional ITPS was alleviated. Moreover, it was observed that, compared with PCM-ITPS1, the temperature further decreased and the thermal short effect was mitigated by a larger degree for PCM-ITPS2, which revealed that the higher latent heat of the phase change of the composite PCM would lead to a better thermal insulation performance.

The solid lines in Fig. 10(c) described the temperature evolutions of different test pieces on the same measure point (shown in Fig. 10(a)). As can be seen, the peak temperature reaches $174.9^{\circ} \mathrm{C}$ at $240 \mathrm{~s}$ for the traditional ITPS while $144.5^{\circ} \mathrm{C}$ at $293 \mathrm{~s}$ for PCM-ITPS1 with a temperature drop of $17.38 \%$ and a time delay of $63 \mathrm{~s}$ as well as $119.0^{\circ} \mathrm{C}$ at $296 \mathrm{~s}$ for PCM-ITPS2 with a temperature drop of $31.96 \%$ and a time delay of $66 \mathrm{~s}$. It further validated that the composite PCM would bring a favorable influence on the heat insulting performance of ITPS.

Moreover, as the reusable performance is an important property for the engineering application of ITPS, the reusability of PCM-ITPS were primarily verified in two aspects. On the one hand, the composite PCM was placed in a heating oven at $150{ }^{\circ} \mathrm{C}$ for $3 \mathrm{~h}$ to verify the leakage state. Actually, it should be noted that the compression process indeed increased the leakage of the composite PCM. Many literatures have studied the leakage issue of composite PCM under phase change cycles. It was observed that increasing the EG mass fraction would effectively decrease the leakage due to the absorption capacity of EG [35]. Moreover, results shown that when the EG content reached $20 \mathrm{wt} \%$, the maximum leakage would be less than $0.5 \%$ [35,42], which is small enough to be ignored. The leakage test results in this work (shown in Fig. 11(a)) further demonstrated the conclusion as no leakage was observed on the filter paper. Therefore, the prepared composite PCM with the mass fraction of $20 \%$ EG in this work can be regarded as no leakage when the temperature of the PCM was over than the melting temperature. On the other hand, the thermal insulation experiment under the laser heat source was repeatedly conducted. Fig. 11(b) illustrated

Table 2

Temperature dependent physical properties of the S304 stainless steel.

\begin{tabular}{|c|c|c|c|c|}
\hline Designation & Value & & & \\
\hline Density $\left(\mathrm{kg} \cdot \mathrm{m}^{-3}\right)$ & 7930 & & & \\
\hline Thermal conductivity $\left(\mathrm{W} \cdot \mathrm{m}^{-1} \cdot{ }^{\circ} \mathrm{C}^{-1}\right)$ & $14.16\left(20^{\circ} \mathrm{C}\right)$ & $17.03\left(200^{\circ} \mathrm{C}\right)$ & $20.07\left(400^{\circ} \mathrm{C}\right)$ & $25.67\left(800^{\circ} \mathrm{C}\right)$ \\
\hline Specific heat capacity $\left(\mathrm{J} \cdot \mathrm{kg}^{-1} \cdot{ }^{\circ} \mathrm{C}^{-1}\right)$ & $479.0\left(20^{\circ} \mathrm{C}\right)$ & $523.7\left(200^{\circ} \mathrm{C}\right)$ & $557.3\left(400^{\circ} \mathrm{C}\right)$ & $615.5\left(800^{\circ} \mathrm{C}\right)$ \\
\hline Young's modulus $(\mathrm{Pa})$ & $2.01 \mathrm{e} 11\left(20^{\circ} \mathrm{C}\right)$ & $1.89 \mathrm{e} 11\left(200{ }^{\circ} \mathrm{C}\right)$ & $1.72 \mathrm{e} 11\left(400{ }^{\circ} \mathrm{C}\right)$ & $1.03 \mathrm{e} 11\left(800^{\circ} \mathrm{C}\right)$ \\
\hline Thermal coefficient of expansion $\left({ }^{\circ} \mathrm{C}^{-1}\right)$ & $1.577 \mathrm{e}-5\left(20^{\circ} \mathrm{C}\right)$ & $1.685 \mathrm{e}-5\left(200^{\circ} \mathrm{C}\right)$ & $1.805 \mathrm{e}-5\left(400^{\circ} \mathrm{C}\right)$ & $2.045 \mathrm{e}-5\left(800^{\circ} \mathrm{C}\right)$ \\
\hline
\end{tabular}




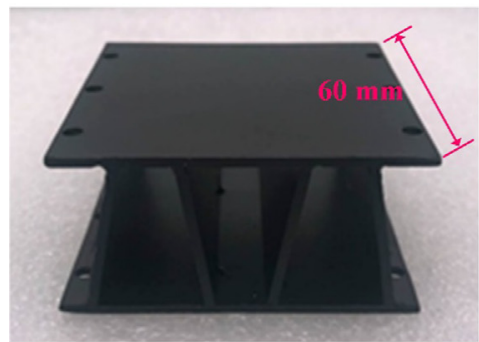

(a)

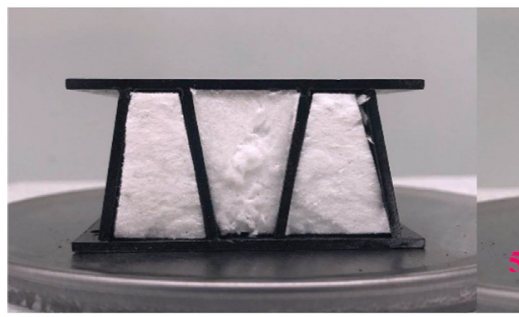

(d)

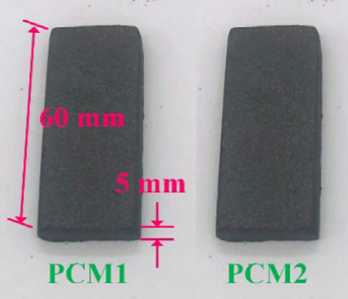

(b)

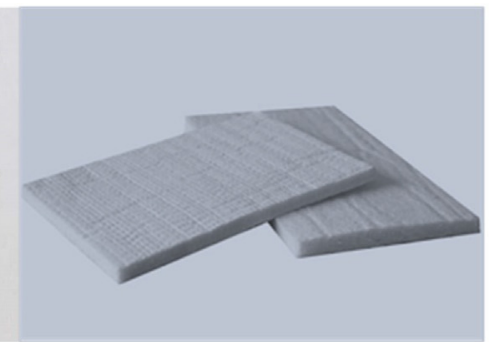

(c)

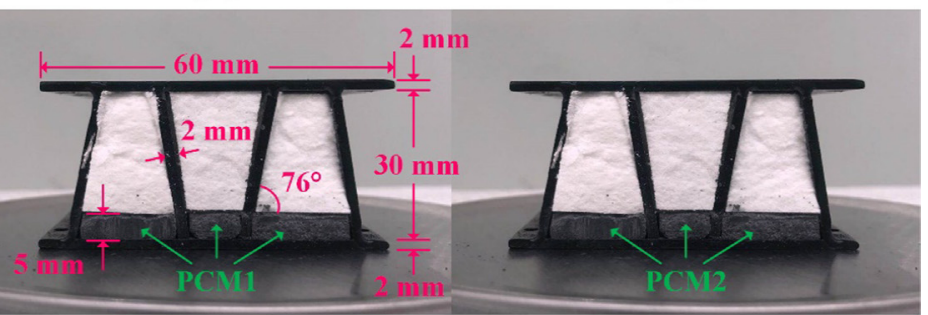

(e)

(f)

Fig. 8. Photographs of (a) the sand blasting structure, (b) the PCM slab specimen, (c) the aerogel insulation fiber, (d) the traditional ITPS, (e) PCM-ITPS1 and (f) PCM-ITPS2.

the thermal protection performance of the same test piece for the repeated times. It was found that no remarkable change was observed in the thermal insulation properties of PCM-ITPS. Therefore, the reusable performance can be guaranteed under the practical service conditions.

\subsection{Numerical simulations of thermal protection performance}

In this section, the transient heat transfer simulation is conducted to investigate the internal heat transfer characteristics of the PCM-ITPS. The transient heat transfer model that simulates the experiment process in Section 3.1 is established. For the heat loads, a uniform heat flux of $100 \mathrm{~kW} / \mathrm{m}^{2}$ is imposed on the TFS for $120 \mathrm{~s}$. Meanwhile, the heat radiation is also applied on the TFS with emissivity of 0.8 and ambient temperature of $283 \mathrm{~K}$. Considering that the geometry, material, thermal load and boundary conditions are uniform along the $z$ direction, as well as the PCM-ITPS is periodic in the $x$ direction, the two-dimensional unit cell analysis model in the $x$-y plane is selected to simulate the typical heat transfer process of PCM-ITPS. Furthermore, the following reasonable assumptions are presented to simplify the numerical analysis:

(a) The thermal resistance on the contact surfaces between different materials is ignored.

(b) The lower surface of BFS is set to be adiabatic.

(c) The convective heat transfer and radiation inside the insulation layer is disregarded.

(d) The volume change of the insulation material and the PCM is not considered.

(e) No liquid motion and only thermal conduction is occurring inside PCM because the composite PCM is form-stable [43].

According to the thermal boundaries and assumptions stated above, the heat transfer simulation is conducted based on the two-dimensional heat conduction equation as follows: $\rho c(T) \frac{\partial T}{\partial t}=\frac{\partial}{\partial y}\left(k(T) \frac{\partial T}{\partial y}\right)+\frac{\partial}{\partial x}\left(k(T) \frac{\partial T}{\partial x}\right)$

where $\rho, c(T)$ and $T$ are density, specific heat, temperature, respectively. $t$ is time and $k(T)$ is thermal conductivity.

Moreover, the TFS is set as the second type of thermal boundary condition and the surface heat radiation effect is considered as follows:

$k(T) \frac{\partial T}{\partial y}=q-\varepsilon \sigma_{s}\left(T_{w}^{4}-T_{0}^{4}\right)$

where $q, \varepsilon, T_{w}$ and $T_{0}$ are heat flux, surface emissivity, surface temperature and ambient temperature, respectively; $\sigma_{s}$ denotes the Stefan-Boltzmann constant, whose value is $5.67 \times 10^{-8} \mathrm{~W} /\left(\mathrm{m}^{2} \cdot \mathrm{K}^{4}\right)$.

Given that phase change process is a highly nonlinear process, the apparent heat capacity method (AHCM) is used to treat the latent heat of phase change [44]. In this way, the phase change process can be introduced into the heat conduction equation. The latent heat is regarded as the high heat capacity of materials in the vicinity of the phase change temperature.

The equivalent heat capacity is summarized as follows:

$C^{A}(T)=\rho L \delta\left(T-T_{m}\right)+C(T)$

where $C^{A}(T)$ is heat capacity, $T_{m}$ is the phase change temperature, $L$ is latent heat, $C(T)$ is a function related to specific heat and temperature as:

$C(T)=\left\{\begin{array}{c}\rho c_{s}, T<T_{m} \\ \frac{\rho c_{s}+\rho c_{l}}{2}+\frac{\rho L}{\tau}, T_{m} \leqslant T \leqslant T_{m}+\tau \\ \rho c_{l}, T>T_{m}+\tau\end{array}\right.$

where subscript " $s$ " and " $l$ " respectively represent solid and liquid, $\tau$ is phase change temperature interval, which is determined to be $3^{\circ} \mathrm{C}$ for the melting.

Then, the two-dimensional heat conduction equation incorporating

Table 3

Temperature dependent physical properties of the aerogel insulation fiber.

\begin{tabular}{|c|c|c|c|c|}
\hline Designation & Value & & & \\
\hline Density $\left(\mathrm{kg} \cdot \mathrm{m}^{-3}\right)$ & 220 & & & \\
\hline Thermal conductivity $\left(\mathrm{W} \cdot \mathrm{m}^{-1} \cdot{ }^{\circ} \mathrm{C}^{-1}\right)$ & $0.021\left(20^{\circ} \mathrm{C}\right)$ & $0.024\left(200^{\circ} \mathrm{C}\right)$ & $0.028\left(400^{\circ} \mathrm{C}\right)$ & $0.034\left(800^{\circ} \mathrm{C}\right)$ \\
\hline Specific heat capacity $\left(\mathrm{J} \cdot \mathrm{kg}^{-1} \cdot{ }^{\circ} \mathrm{C}^{-1}\right)$ & $549\left(20^{\circ} \mathrm{C}\right)$ & $526\left(200^{\circ} \mathrm{C}\right)$ & $504\left(400^{\circ} \mathrm{C}\right)$ & $453\left(800^{\circ} \mathrm{C}\right)$ \\
\hline
\end{tabular}




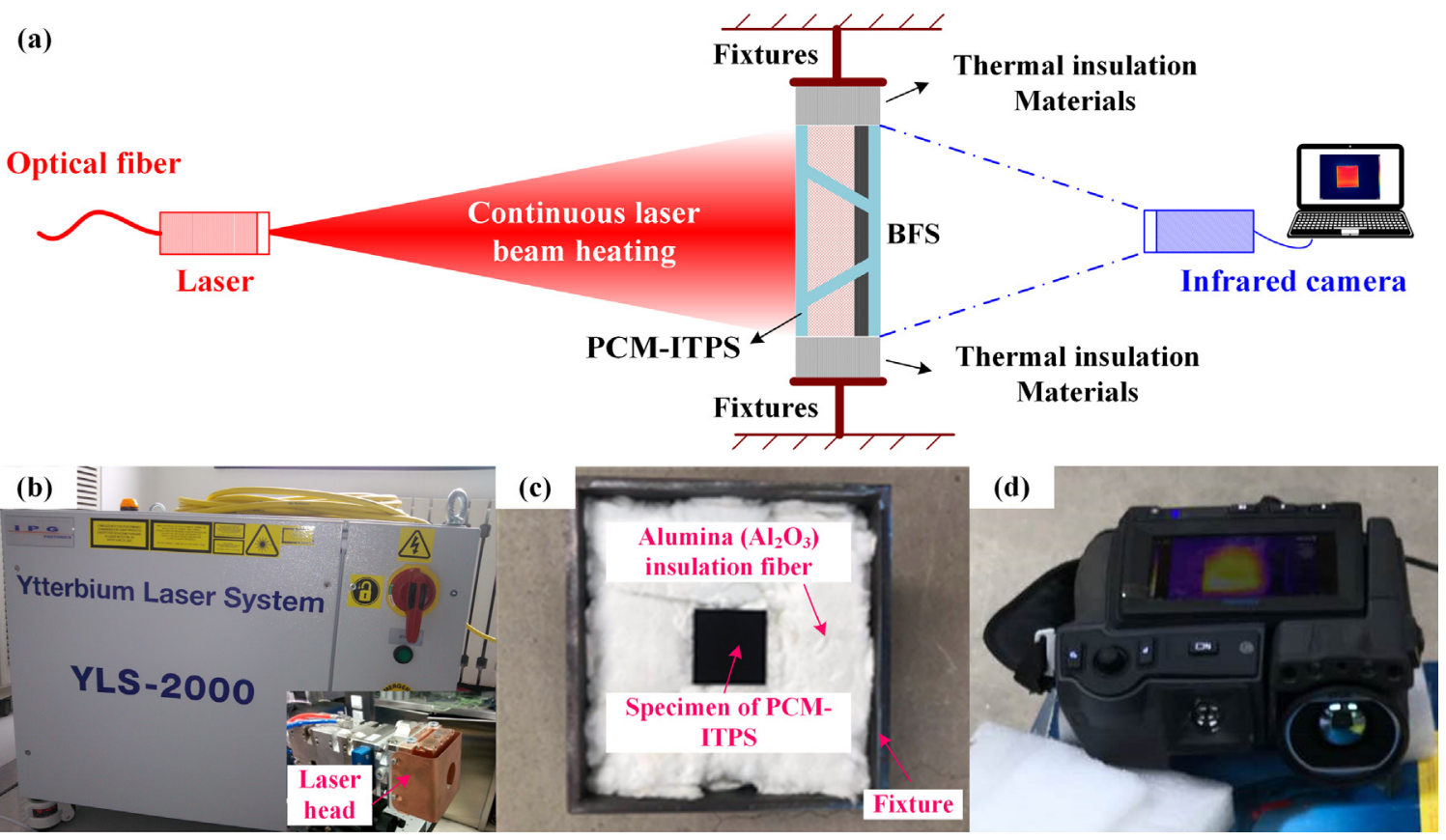

Fig. 9. (a) Schematic diagram of the experiment setup. Photos of (b) YLS-2000 laser system, (c) Fixture and (d) Infrared imaging system.

(a)

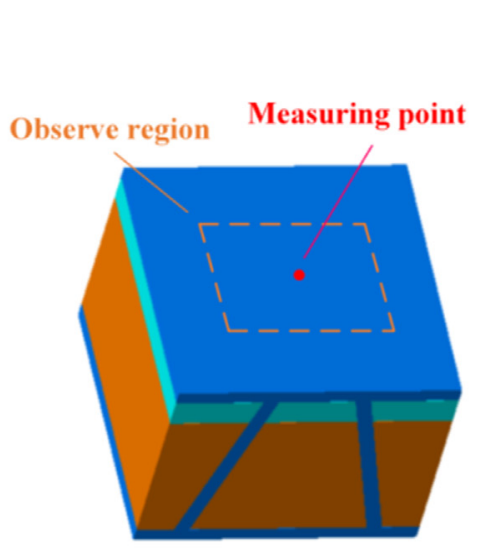

(c)

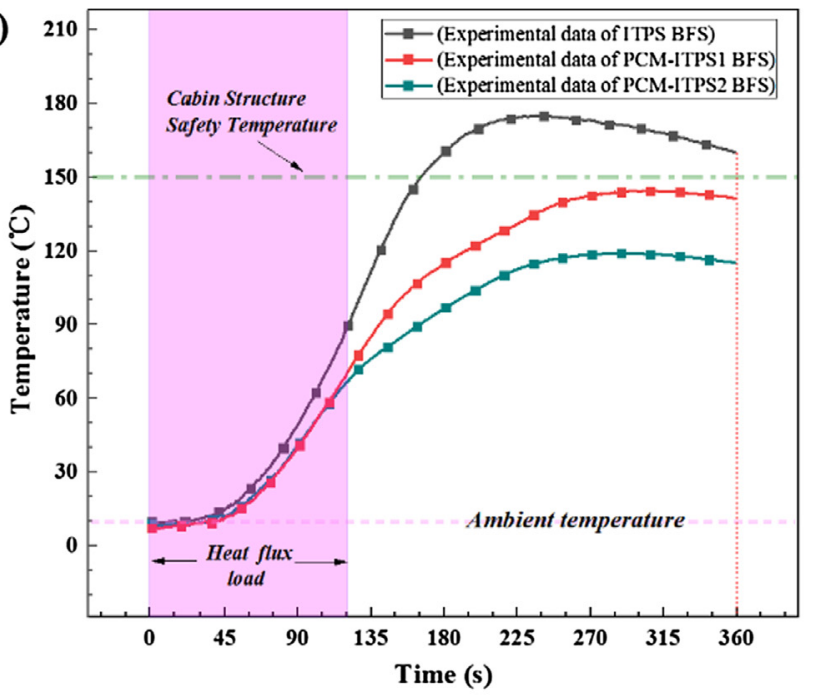

(b)

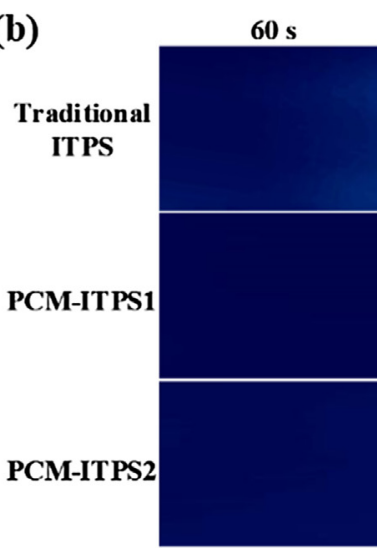

$120 \mathrm{~s}$

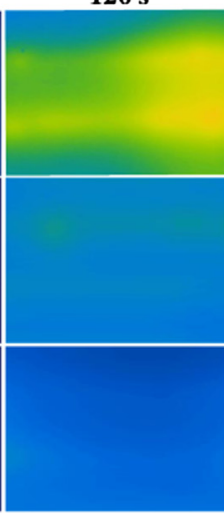

$180 \mathrm{~s}$

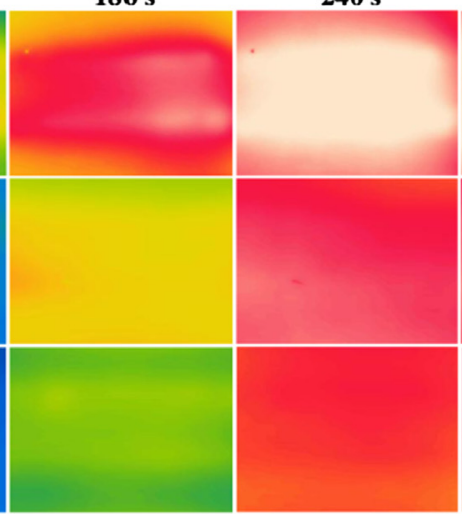

$300 \mathrm{~s}$

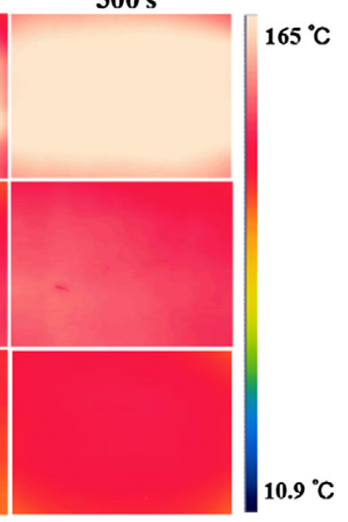

Fig. 10. (a) Illustration of measuring positions. Graphs of (b) the temperature distribution and (c) temperature evolutions during the experiment process. 


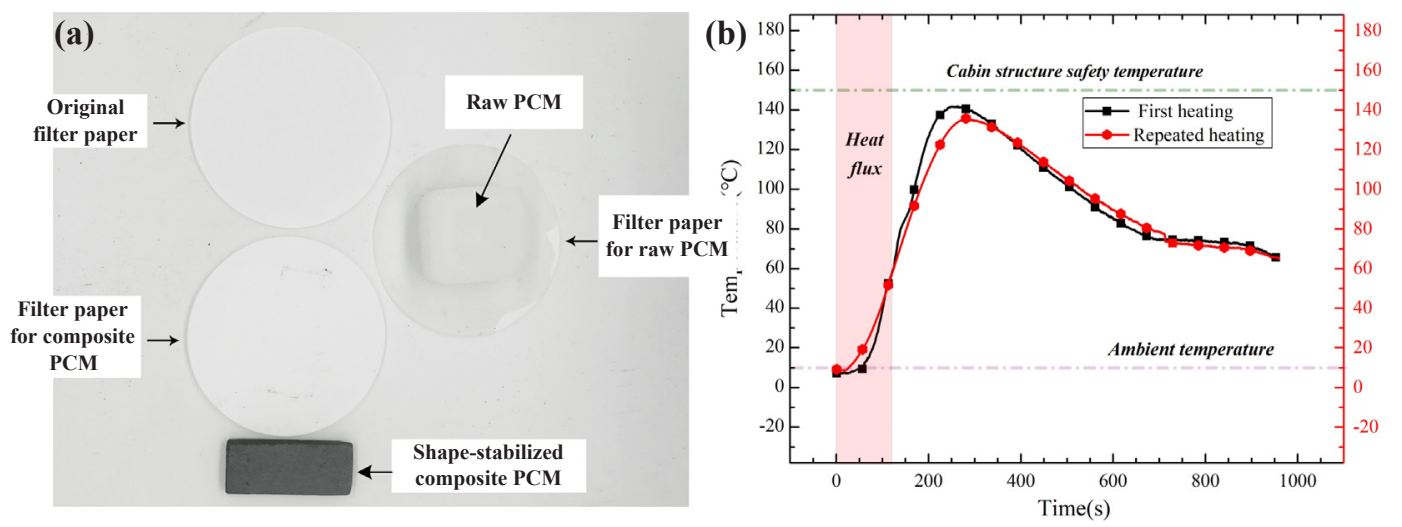

Fig. 11. (a) Leaking test for the composite PCM and (b) thermal protection performance of the same test piece for the repeated tests.

the AHCM expressed by Dirac function can be rewritten as follows:

$C^{A}(T) \frac{\partial T}{\partial t}=\frac{\partial}{\partial x}\left[k(T) \frac{\partial T}{\partial x}\right]+\frac{\partial}{\partial y}\left[k(T) \frac{\partial T}{\partial y}\right]$

where $k(T)$ is the thermal conductivity function related to the phase change temperature:

$k(T)=\left\{\begin{array}{l}k_{s}(T), T<T_{m} \\ k_{l}(T), T>T_{m}\end{array}\right.$

Considering that the heat transfer problem in PCM-ITPS is a complicated non-linear transient problem involving phase change, heat radiation, varying material properties, the finite element method (FEM) is used to discretize the above transient heat conduction equation. The discretized FEM matrix formulation can be written as:

$[\boldsymbol{C}]\{\dot{\boldsymbol{T}}\}+[\boldsymbol{K}]\{\boldsymbol{T}\}=\{\boldsymbol{Q}\}$

Here, $[\boldsymbol{C}],\{\boldsymbol{T}\},[\boldsymbol{K}],\{\boldsymbol{Q}\}$ are the thermal capacitance matrix, temperature vector, thermal conductivity matrix, and nodal heat load vector, respectively.

In this paper, the numerical solutions of Eq. (8) have been carried out with the general finite element solver ABAQUS Version 6.12 programmer [45] and Euler method is adopted to march the solution in time [46]. The FEM computational grid is a structured grid generated by ABAQUS, the analysis element type is set to be DC2D4, and the mesh number is 13,700 .

Fig. 12(a) shows the boundary conditions of numerical model. Fig. 12(b) shows the comparison between the traditional ITPS and PCM-ITPS on the temperature with respect to the reentry time on the BFS. In the numerical simulation of ground test condition, the input heat flux was the same as the laser power in the experiment. The calculation method and the other assumptions were completely consistent with the aforementioned heat transfer numerical analysis model. The dash line in Fig. 12(b) given the temperature results obtained through the numerical simulation. By comparison, it confirmed that temperature evolution trend of the numerical simulation well agreed on that of the experiment. Besides, the maximum temperature values of the traditional ITPS, PCM-ITPS1 and PCM-ITPS2 were $181.0^{\circ} \mathrm{C}, 152.0^{\circ} \mathrm{C}$ and $126.0^{\circ} \mathrm{C}$ based on the experiment results while $174.9^{\circ} \mathrm{C}, 144.5^{\circ} \mathrm{C}$ and $119.0^{\circ} \mathrm{C}$ based on the simulation results. Compared with the experiment results, the errors on the maximum temperature of the simulation model for the traditional ITPS, PCM-ITPS1 and PCM-ITPS2 are 3.39\%, $4.93 \%$ and $5.56 \%$, respectively, which meant that the proposed simulation model for the PCM-ITPS was enough accurate in predicting the thermal performance.

Fig. 12(c) shows the comparison between the traditional ITPS and PCM-ITPS1 on the temperature field at $120 \mathrm{~s}$. It can be seen that the thermal short effect exists in both the traditional ITPS and PCM-ITPS. However, compared with the traditional ITPS, the thermal short effect is effectively reduced in the PCM-ITPS. Additionally, in PCM-ITPS, the temperature near the BFS is gradual, which indicates that the PCM has an absorption effect on the heat conducted through the thermal bridge. Fig. 12(d) shows the temperature evolutions on the featured locations of PCM-ITPS1 during the reentry process. The result on Node1 indicates that the TFS reaches its peak temperature at around $120 \mathrm{~s}$ when the input heat flux stops. Apparently, the peak temperature of TFS is lower than the radiation equilibrium temperature, which is determined by the input heat flux, surface emissivity and ambient temperature, for the insufficient heat flux load time. The results on Node2-Node8 describe the temperature variations in the heat insulation layer. It can be seen that the peak temperature is successively achieved along the thickness direction and decreases from $508{ }^{\circ} \mathrm{C}$ to $170{ }^{\circ} \mathrm{C}$ due to the low thermal conductivity of the aerogel insulation fiber. Furthermore, the results on Node9 and Node10 display the temperature variations in the PCM layer and BFS, respectively. It manifests that the PCM layer has the similar temperature change trend with the BFS for the comparable thermal conductivity.

\subsection{Discussions on the thermal protection performance of PCM-ITPS}

All in all, based on the experiment and simulation results, it can be concluded that PCM-ITPS processes better thermal insulation performance than the traditional ITPS. In order to interpret the superior on heat insulation clearer for the PCM-ITPS, the heat transfer paths in traditional ITPS and PCM-ITPS are delineated in Fig. 13. And the performance advantages of PCM-ITPS can be elaborated as follows:

(1) Compared with the traditional ITPS, a considerable proportion of the heat that transfers downward through the thermal bridge can be conducted into the PCM layer due to the high thermal conductivity of composite PCM.

(2) The heat protection capacity of PCM-ITPS increases as the shapedstabilized composite PCM layer can absorb a large amount of heat by the phase change reaction. Therefore, the conducted heat can be effectively absorbed by the PCM layer without a great temperature rise.

In this way, the thermal short efforts can be effectively alleviated in PCM-ITPS.

\section{Load bearing capacity analysis of PCM-ITPS}

Although the load-bearing structure of PCM-ITPS has not changed with respect to the traditional ITPS, the characteristics of temperature distribution have substantially changed due to the addition of PCM, which would dramatically affect the load-bearing capability. Considering that, the effects of PCM addition on the load bearing structure must be carefully investigated. 
(a)

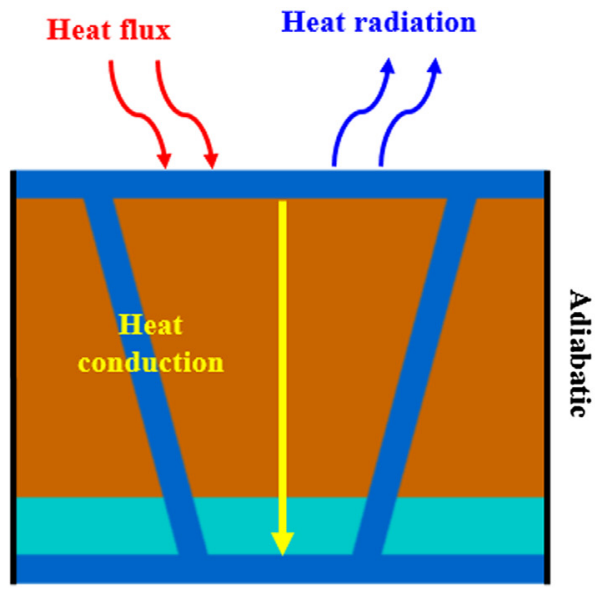

Convection

(c)

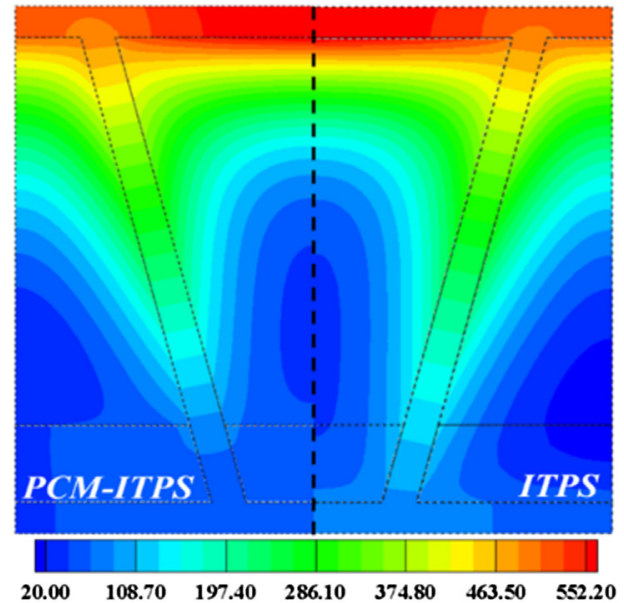

(b)

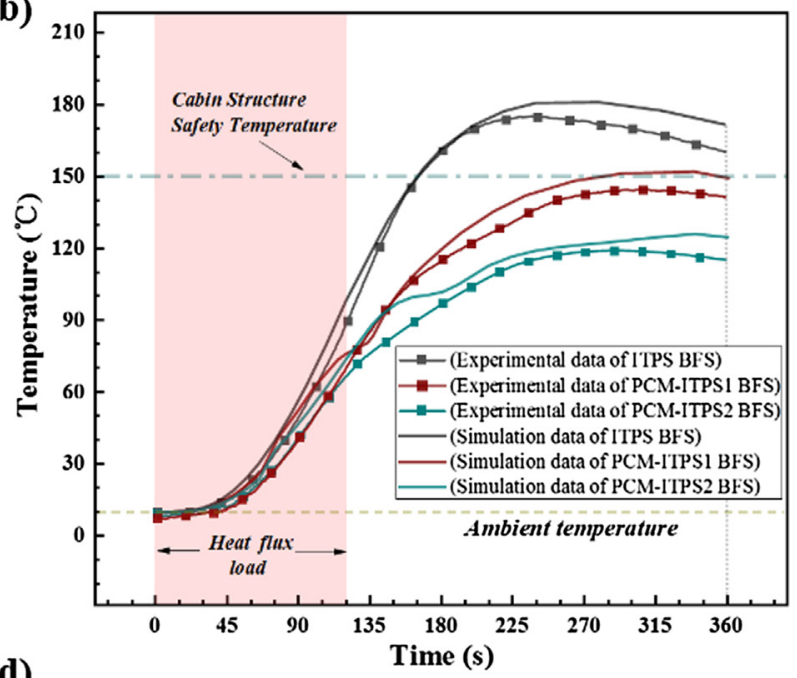

(d)

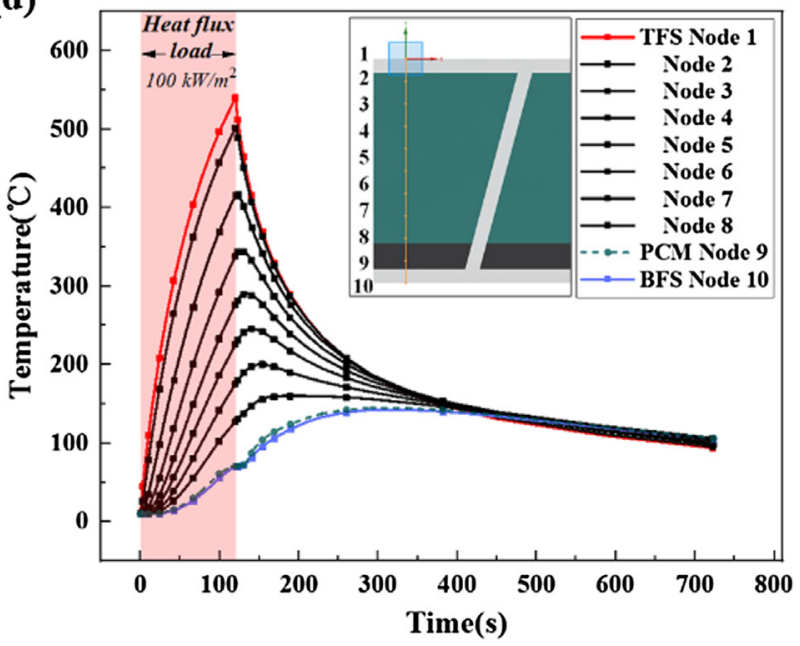

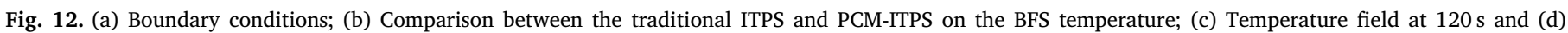
temperature evolutions of PCM-ITPS1.

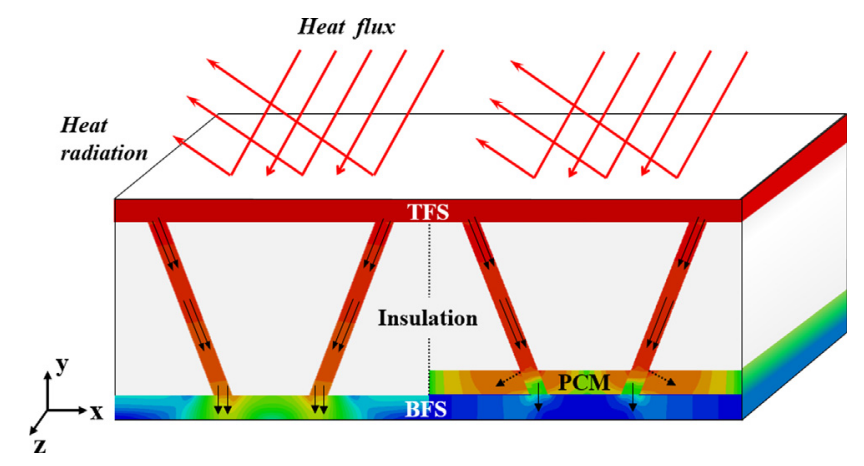

Fig. 13. Illustration of the heat transfer paths in traditional ITPS and PCM-ITPS.

Studies have indicated that the corrugated core ITPS will produce the maximum stress and displacement at the critical time, which is known as the moment when the maximum temperature difference between the top face sheet and bottom face sheet occurs [25]. Therefore, only the structural field analysis at the critical time is needed to check the structural safety, which can avoid hundreds of time-consuming simulations. Additionally, considering the fact that the temperature field has a great influence on the structural load bearing performance while the influence of the stress field on the temperature distribution is substantially negligible, the thermal stress and deflection analysis of PCMITPS can be conducted after temperature field at the critical time is obtained by the sequential thermal-mechanical coupling method. And the constitutive relationship used in thermal-mechanical coupling analysis can be written as follows:

$\left\{\begin{array}{c}\varepsilon_{x}=\frac{\partial u}{\partial x}=\frac{1}{E}\left[\sigma_{x}-\mu\left(\sigma_{y}+\sigma_{z}\right)\right]+\alpha \Delta T \\ \varepsilon_{y}=\frac{\partial v}{\partial y}=\frac{1}{E}\left[\sigma_{y}-\mu\left(\sigma_{z}+\sigma_{x}\right)\right]+\alpha \Delta T \\ \varepsilon_{z}=\frac{\partial w}{\partial z}=\frac{1}{E}\left[\sigma_{z}-\mu\left(\sigma_{x}+\sigma_{y}\right)\right]+\alpha \Delta T \\ \gamma_{x y}=\frac{\tau_{x y}}{G}, \quad \gamma_{y z}=\frac{\tau_{y z}}{G}, \quad \gamma_{z x}=\frac{\tau_{z x}}{G}\end{array}\right.$

where $\varepsilon_{x}, \varepsilon_{y}, \varepsilon_{z}$ is thermal strain, $\gamma_{x y}, \gamma_{y z}, \gamma_{z x}$ is shear strain, $u, v, w$ is displacement component, $\sigma_{x}, \sigma_{y}, \sigma_{z}$ is stress, $\alpha$ is thermal expansion coefficient, $\Delta T$ is temperature difference between two moments, $E$ is elastic modulus, $G$ is shear modulus, $\mu$ is Poisson's ratio.

In order to determine the mechanical responses of the PCM-ITPS, the numerical simulation will be carried out by utilizing the finite element software ABAQUS. The unit cell part of the model marked in Fig. 14(a) is the quarter-symmetrical model adopted in this paper. The hypersonic vehicle TPS is usually connected to the cabin by bolts and a schematic diagram of its actual connection is attached in Fig. 14(b). A, $\mathrm{B}, \mathrm{C}$, and D denote the four faces around the model. Among them, A and $\mathrm{B}$ are the actual boundaries, which are usually connected to the bulkhead; C and D are symmetrical boundary conditions. Under this circumstance, the boundary conditions for the mechanical simulation can be summarized as follows: 


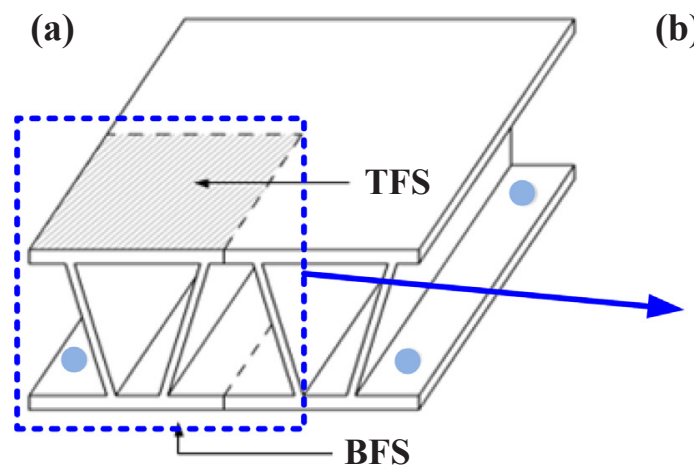

This side is fixed (b)

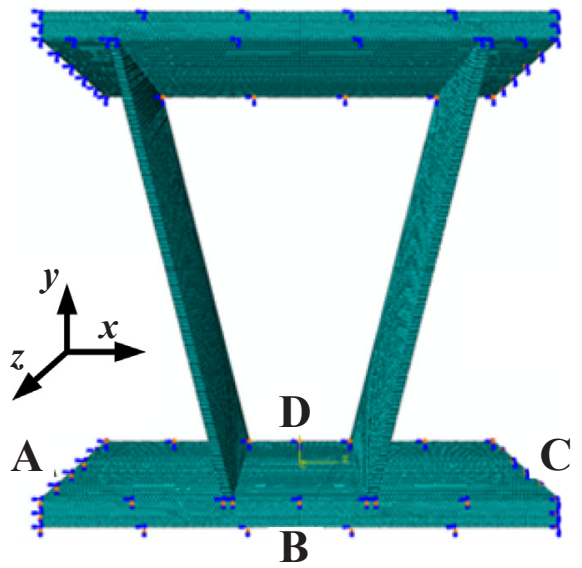

Fig. 14. Schematic diagram of calculating model boundary conditions and meshing.

(1) The bottom surface of A and B are constrained on the translation and rotation degrees in $\mathrm{X}$ and $\mathrm{Z}$ directions.

(2) The top surface of A and B is only constrained on the rotation degree.

(3) C and D are symmetrical boundary conditions, which means C is restricted on the translation in $\mathrm{X}$ direction, and $\mathrm{D}$ is restricted on the translation in $\mathrm{Z}$ direction.

The FEM computational grid is a structured grid with the type of C3D8R generated by ABAQUS and the volume mesh number of the domain is 84,360 . The heat flux loads and thermal analysis model in this section are consistent with those in Section 3.2. Based on the obtained thermal responses, the corresponding critical time is $120 \mathrm{~s}$ for both the traditional ITPS and PCM-ITPS. And then the Von Mises stress and displacement of PCM-ITPS and the traditional ITPS shown in
Fig. 15 can be acquired. The simulation results shown that the maximum Von Mises stress and displacement of PCM-ITPS were $215 \mathrm{MPa}$ and $0.45 \mathrm{~mm}$, respectively, while those of the traditional ITPS were $209 \mathrm{MPa}$ and $0.43 \mathrm{~mm}$, respectively. It can be seen that the maximum stress and displacement values of the traditional ITPS are slightly smaller than those in PCM-ITPS. This is because PCM-ITPS leads to a larger temperature difference than the traditional ITPS with the same size, which has a reduction effect to the load bearing capacity. Therefore, the optimization design of PCM-ITPS under actual working conditions is necessary to take full advantage of the thermal insulation property in the premise of guaranteeing the load bearing capacity.

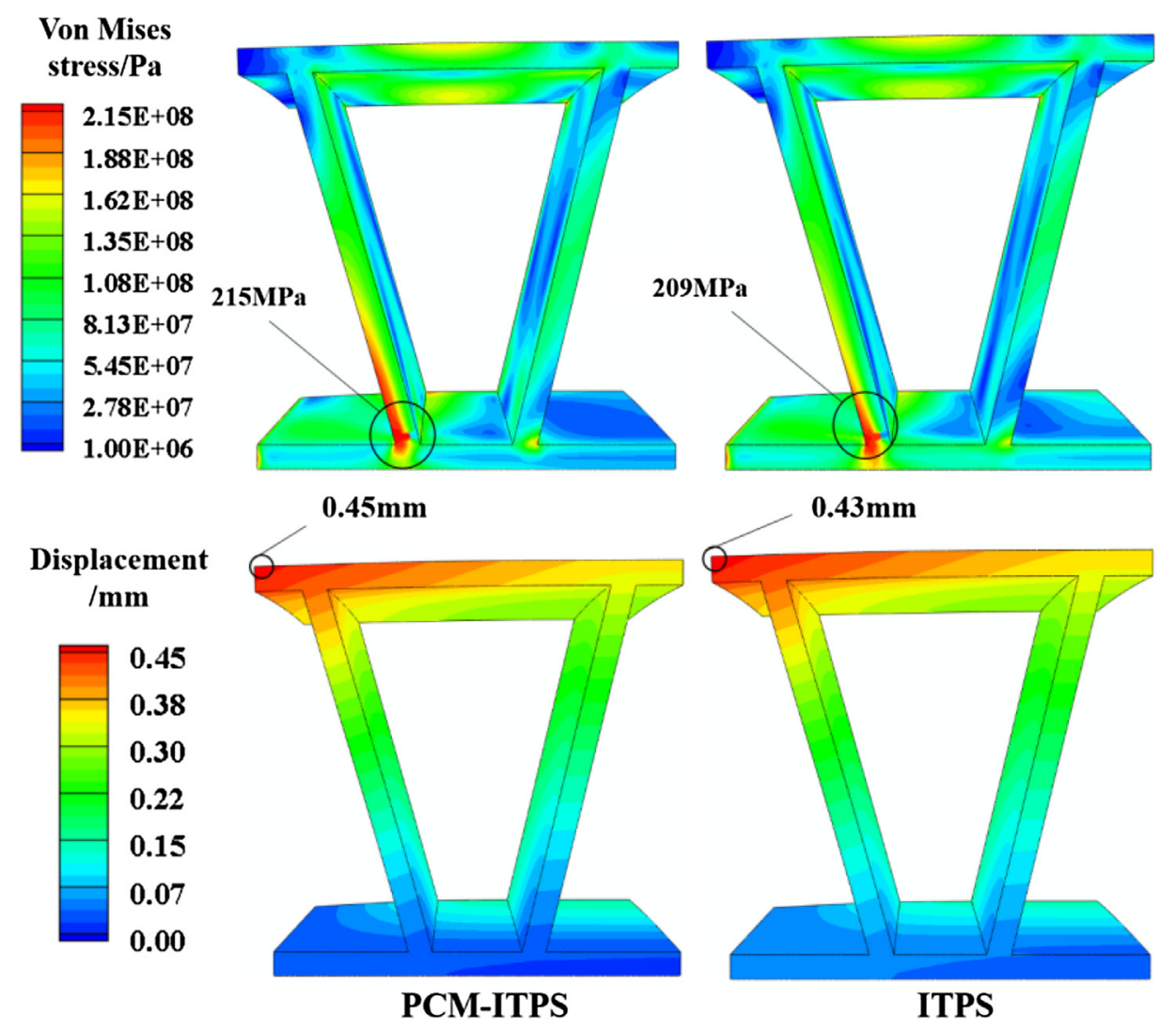

Fig. 15. Von Mises stress and displacement fields for PCM-ITPS and the traditional ITPS. 


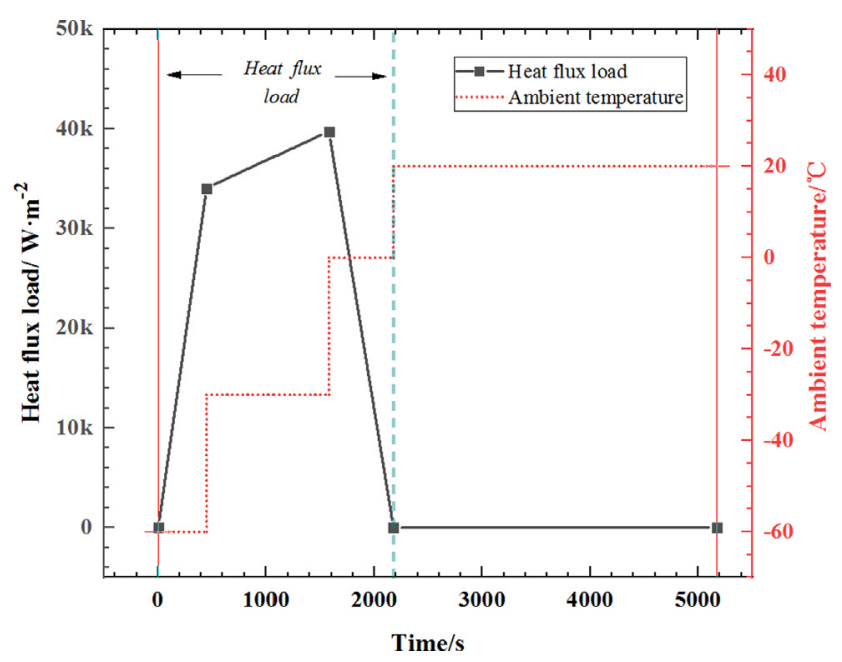

Fig. 16. Heating profile of a Space Shuttle-like vehicle during the re-entry.

\section{Design optimization procedure of PCM-ITPS under actual reentry environment}

In order to further promote the structural efficiency of ITPS, a design optimization procedure is established in this section to obtain the optimal design of PCM-ITPS under the re-entry fight conditions of hypersonic vehicles.

\subsection{Statement of the optimization problem}

The design process for the PCM-ITPS can be mathematically formulated as an optimization model. The goal of the optimization is to obtain the lightest structure while satisfying all the constraints by designing the geometry parameters. For the current analysis, the following five critical constraints are considered in the optimization problem:

(1) The hypersonic vehicle generally requires that the maximum temperature of the BFS does not exceed $150{ }^{\circ} \mathrm{C}$ to ensure the safety of the equipment in the cabin.

(2) The maximum temperature of the PCM is requested to be fewer than the maximum workable temperature $\left(200^{\circ} \mathrm{C}\right)$ to avoid decomposition and guarantee reusability.

(3) The maximum Von Mises stress of the PCM-ITPS is fewer than 156.5 MPa (The bearing structure of the model is Ti-6Al-4V [6], whose yield strength of titanium alloy is $313 \mathrm{MPa}$, and the safety factor is taken as 2).

(4) The maximum displacement of the structure is less than the limit of $6 \mathrm{~mm}$ [6] to maintain the smooth aerodynamic profile of the vehicle.

(5) The web buckling characteristic value is larger than 1.25 [6] to withstand the global/local buckling due to mechanical and thermal stress.

Based on the aforementioned constraints, the mathematical expression of the PCM-ITPS optimization model can be written as follows:

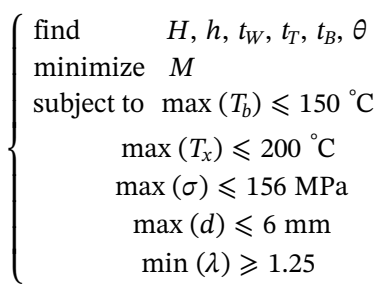

where $M$ is the weight per square meter of the PCM-ITPS, $T_{b}$ is the temperature of the BFS, $T_{x}$ is the temperature of the PCM, $\sigma$ is the Von Mises stress of the load-bearing structure, $d$ is the deflection of the TFS, and $\lambda$ is the web buckling characteristic value.

\subsection{Thermo-structural responses of PCM-ITPS in actual reentry environment}

The heat transfer and the structural field analysis are successively performed in this section to obtain the thermo-structural responses involved in the optimization model.

Given that the aerodynamic heating flux is imposed on the external surface of TFS during the re-entry flight, the transient heat transfer analysis of the PCM-ITPS is first conducted to achieve the following purposes:

(1) Obtain the maximum temperature of the BFS during the re-entry process.

(2) Obtain the maximum temperature of the PCM during the re-entry process.

(3) Determine the most critical time during the re-entry process and provide the temperature distribution at that critical time as the thermal loads for the structural field analysis.

The analysis model proposed in Section 3.2 is utilized to describe the transient heat transfer process of PCM-IPTS. The thermal loads, aerodynamic pressure and boundary conditions of Space Shuttle-like vehicle in Ref. [6] are adopted in this work. Fig. 16 schematically illustrates the heating profile used for the preliminary design.

\subsection{Implementation of the optimization procedure}

Given that the optimization platform will perform a large number of thermo-structural analyses, this paper uses Python programming language to parametrically construct the analysis model. The whole optimization design procedure can be elaborated as follows:

(1) The two-dimensional transient heat transfer simulation is used to calculate the temperature of the structure.

(2) The Python program is used to find the maximum temperature of each part during the entire heat transfer process and the critical time when the maximum temperature difference between the TFS and the BFS.

(3) The temperature field of the load bearing structure at the critical time is exported, and the two-dimensional temperature field is transformed into a three-dimensional temperature field model by interpolation technique.

(4) The three-dimensional temperature field is imposed on the FEM model as the thermal loads and then the thermal stress, the displacement as well as the buckling characteristic value is calculated. One thing should be noted here that the calculation method of the buckling characteristic value refers to Ref. [6].

(5) A global solution algorithm, namely, multi-island genetic algorithm, is employed in the optimization platform to obtain the global optimal solutions.

By adopting this method, the entire optimization platform can realize the integrated design of PCM-ITPS. Fig. 17 shows the optimization design flowchart.

\subsection{Optimization results and discussions}

Fig. 18 shows the variation of the structural design parameters during the optimization process. After hundreds of thermo-structural analyses, the fluctuation of all the design variables begins to decrease, and then the optimization model approaches to the optimal solution.

The design parameters and optimization results are listed in Table 4. 


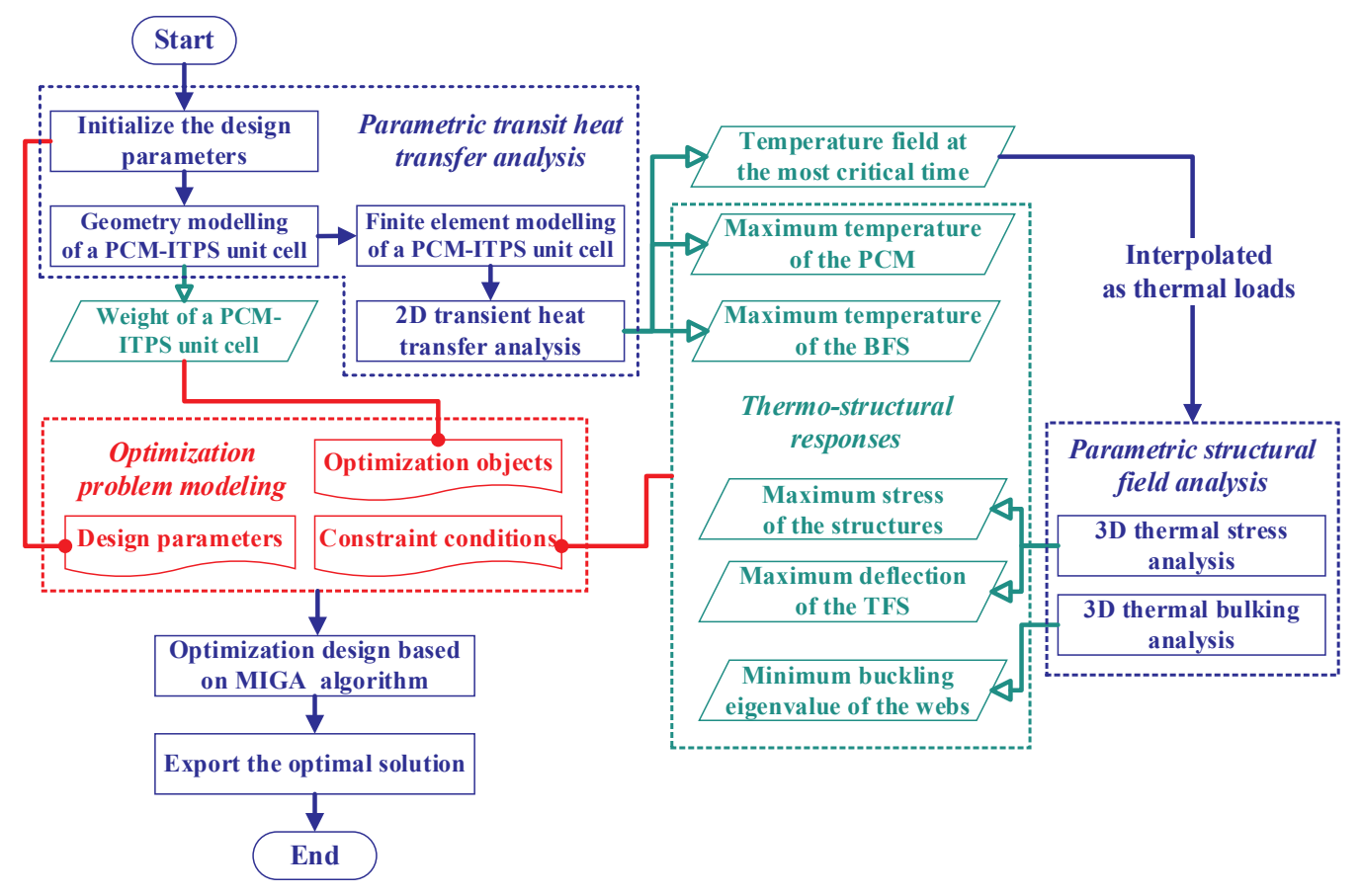

Fig. 17. Optimization design flowchart of PCM-ITPS.

It can be seen that the constrains including maximum temperature of the PCM layer, structural stress and structural displacement become inactive in both optimization models as the corresponding values for most design points are far less than the allowable values. Additionally, the thermal stress and deformation of PCM-ITPS are smaller than that of traditional ITPS as well as the buckling characteristic value of PCMITPS is larger than that of traditional ITPS, which shows that PCM-ITPS alleviates the mismatch caused by thermal bridge effect in traditional ITPS. Moreover, from weight and height standpoints, the optimized PCM-ITPS achieved a reduction of $14.32 \%$ in weight and a decrease of $46.09 \%$ in thickness compared with the optimized traditional ITPS. It indicates that in addition to the advantage of lightweight, the PCM-ITPS has better thickness reduction effect and increases the efficiency of the ITPS structure, which is consistent with the original intention of the ITPS.

\section{Conclusions}

In this paper, a new type of corrugated sandwich panel ITPS structure incorporating with shaped-stabilized composite PCM layer is

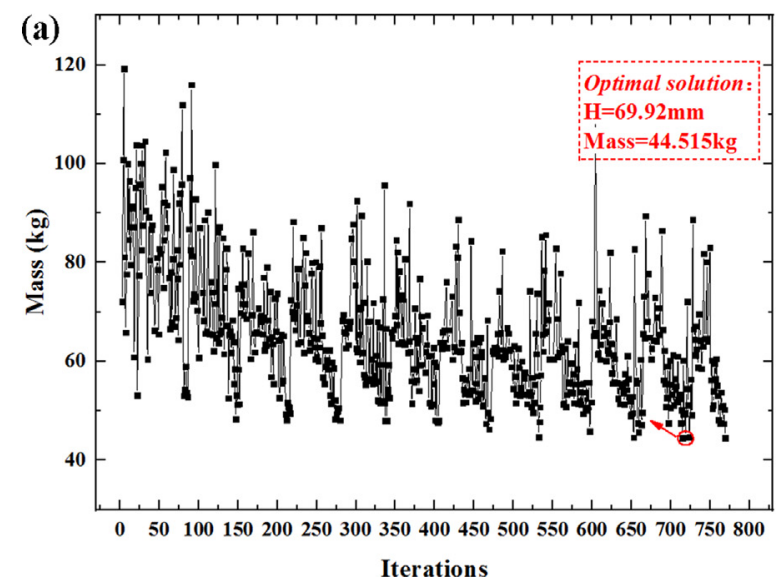

Table 4

Design parameters and optimization results of different ITPS models.

\begin{tabular}{llllll}
\hline & Name & $\begin{array}{l}\text { Initial } \\
\text { value }\end{array}$ & Range & $\begin{array}{l}\text { Optimized } \\
\text { traditional } \\
\text { ITPS }\end{array}$ & $\begin{array}{l}\text { Optimized } \\
\text { PCM-ITPS }\end{array}$ \\
\hline Design parameters & $H(\mathrm{~mm})$ & 140 & $60-160$ & 129.7 & 69.92 \\
& $H(\mathrm{~mm})$ & 10 & $5-30$ & - & 11.07 \\
& $t_{B}(\mathrm{~mm})$ & 6 & $1-7$ & 1.81 & 1.71 \\
& $t_{T}(\mathrm{~mm})$ & 2 & $1-4$ & 1.21 & 1.30 \\
& $t_{W}(\mathrm{~mm})$ & 3 & $1-4$ & 1.34 & 1.16 \\
& $\theta\left({ }^{\circ}\right)$ & $82^{\circ}$ & $75^{\circ}-85^{\circ}$ & 78.61 & 82.17 \\
Responses & $M\left(\mathrm{~kg} / \mathrm{m}^{2}\right)$ & 90.120 & - & 51.950 & 44.515 \\
& $T_{B}\left({ }^{\circ} \mathrm{C}\right)$ & 126.50 & - & 149.82 & 148.65 \\
& $\sigma(\mathrm{MPa})$ & 129.4 & - & 73.7 & 58.6 \\
& $d(\mathrm{~mm})$ & 1.40 & - & 1.26 & 0.67 \\
& $\lambda(-)$ & 4.946 & - & 1.314 & 1.883 \\
\hline
\end{tabular}

proposed. Compared with the traditional ITPS, PCM-ITPS has the advantages of lightweight and structural efficiency by effectively alleviating the thermal bridge phenomenon and promoting the heat

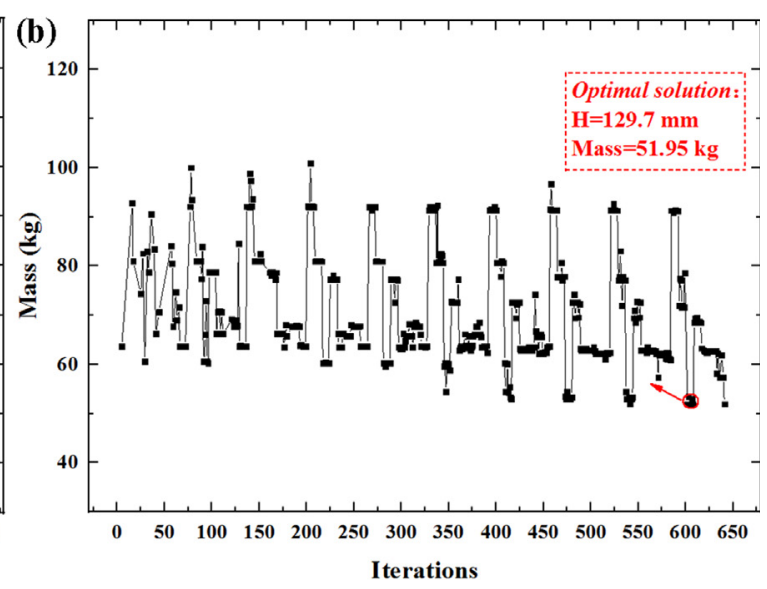

Fig. 18. Illustration of the optimization process for (a) PCM-ITPS and (b) the traditional ITPS. 
insulation capacity. In this work, the thermal protection capability of PCM-ITPS is validated by both experiment test and numerical simulation. And then, the load bearing performance is further studied. Eventually, an optimization procedure suitable for the practical reentry environment is established. The following conclusions can be summarized:

(1) The simple manufacture property of PCM-ITPS can be guaranteed. The conventional corrugated core sandwich structure is maintained so that the additional process on the web can be avoided, which also ensures the load bearing capacity of PCM-ITPS. Moreover, both the shaped-stabilized composite PCM and the heat insulation material are soft enough to be filled into the corrugated sandwich.

(2) The thermal protection performance of PCM-ITPS has been investigated by the thermal insulation experiment in this paper. Experiment results demonstrate that PCM-ITPS processes better insulation capacity than the traditional ITPS. PCM-ITPS can considerably mitigate the thermal bridge phenomenon, and the temperature unevenness observed in the experiment is obviously reduced. Moreover, compared with the traditional ITPS, the maximum temperature of the BFS for PCM-ITPS with the same size decreased by $18.46 \%$.

(3) The transient heat transfer model is established in the paper to further investigate the internal heat transfer characteristics of PCMITPS. By comparison, it can be seen that experimental and simulation results show agreement with each other on the heat transfer performance, which demonstrates the validity of the established analysis model. Moreover, the simulation results indicate that, compared with the traditional ITPS, a large amount of heat that conducted into the BFS by the webs is guided into the PCM layer due to the high thermal conductivity and then absorbed by the PCM due to the heat storage capacity. Therefore, the thermal short efforts can be effectively alleviated in PCM-ITPS.

(4) A general design optimization procedure for PCM-ITPS is established in this work. Results shown that the optimized PCM-ITPS structure decreases the mass and thickness by $14.32 \%$ and $46.09 \%$ compared with the optimized traditional ITPS structure. It proves that PCM-ITPS processes lightweight and thickness reduction advantages in TPS design.

\section{Declaration of Competing Interest}

The authors declared that they have no conflicts of interest to this work.

\section{Acknowledgement}

Financial supports from National Natural Science Foundation of China (Grant No. 11902322) and National Defense Basic Scientific Research program of China (No. JCKY2016130B009) are gratefully acknowledged.

\section{References}

[1] M. Ferraiuolo, A. Riccio, M. Gigliotti, D. Tescione, R. Gardi, G. Marino, Thermostructural design of a flying winglet experimental structure for the EXPERT re-entry test, J. Heat Transfer 131 (2009) 071701.

[2] C.C. Poteet, H. Abu-Khajeel, S. Hsu, Preliminary Thermal-mechanical sizing of a metallic thermal protection system, J. Spacecraft Rockets 41 (2012) 173-182.

[3] S. Chesterman, B. Pouligny, Theoretical prediction of thermal conductivity for thermal protection systems, Appl. Therm. Eng. 49 (2012) 124-130.

[4] J.T. Dorsey, R.R. Chen, K.E. Wurster, C. Poteet, Metallic thermal protection system requirements, environments, and integrated concepts, J. Spacecraft Rockets 41 (2004) 162-172.

[5] M.L. Blosser, R.K. Bird, R.R. Chen, J.T. Dorsey, C.C. Poteet, I.H. Schmidt, K. Wurster, Development of advanced metallic-thermal-protection system prototype hardware, J. Spacecraft Rockets 41 (2015) 183-194.

[6] S. Bapanapalli, O. Martinez, C. Gogu, B. Sankar, M. Blosser, Analysis and design of corrugated-core sandwich panels for thermal protection systems of space vehicles,
AIAA/ASME/ASCE/AHS/ASC Structures, Structural Dynamics, \& Materials Conference AIAA/ASME/AHS Adaptive Structures Conference, (2006).

[7] D. Villanueva, R. Haftka, B. Sankar, Accounting for future redesign in the optimization of an integrated thermal protection system, AIAA/ASME/ASCE/AHS/ASC Structures, Structural Dynamics \& Materials Conference AIAA/ASME/AHS Adaptive Structures Conference AIAA, (2013).

[8] B. Ravishankar, B. Sankar, R. Haftka, Homogenization of integrated thermal protection system with rigid insulation bars, in: AIAA/ASME/ASCE/AHS/ASC Structures, Structural Dynamics, \& Materials Conference AIAA/ASME/AHS Adaptive Structures Conference, 2013.

[9] A.R. Brewer, Edgewise compression testing of STIPS-0 (Structurally Integrated Thermal Protection System), 2011.

[10] C.A. Steeves, H. Ming, P.T. Maxwell, A. Evans, Design of a robust, multifunctional thermal protection system incorporating zero expansion lattices, Am. Soc. Mech. Eng. 53 (2007) 255-260.

[11] O.A. Martinez, B.V. Sankar, R.T. Haftka, S.K. Bapanapalli, M. Blosser, Micromechanical analysis of composite truss-core sandwich panels for integral thermal protection systems, AIAA J. 45 (2012) 2323-2336.

[12] O.A. Martinez, A. Sharma, B.V. Sankar, R.T. Haftka, M. Blosser, Thermal force and moment determination of an integrated thermal protection system, AIAA J. 48 (2010) 119-128.

[13] O. Martinez, B. Sankar, R. Haftka, M. Blosser, Two-dimensional orthotropic plate analysis for an integral thermal protection system, AIAA J. 50 (2012) 387-398.

[14] L. Gu, Y. Wang, S. Shi, C. Dai, M. Transfer, An approximate analytical method for nonlinear transient heat transfer through a metallic thermal protection system, Int. J. Heat Mass Transf. 103 (2016) 582-593.

[15] L. Gu, Y. Wang, S. Shi, C. Dai, An approach for bending and transient dynamic analysis of integrated thermal protection system with temperature-dependent material properties, Compos. Struct. 159 (2017) 128-143.

[16] W. Kai, R. He, X. Cheng, R. Zhang, Y. Pei, D. Fang, Fabrication and mechanical properties of lightweight $\mathrm{ZrO}_{2}$ ceramic corrugated core sandwich panels, Mater. Des. 64 (2014) 91-95.

[17] W. Kai, R. He, X. Cheng, R. Zhang, Y. Pei, D. Fang, A lightweight, high compression strength ultra high temperature ceramic corrugated panel with potential for thermal protection system applications, Mater. Des. 66 (2015) 552-556.

[18] W. Kai, K. Wang, X. Cheng, P. Yong, M. Li, X. Yang, Structural and thermal analysis of integrated thermal protection systems with $\mathrm{C} / \mathrm{SiC}$ composite cellular core sandwich panels, Appl. Therm. Eng. 131 (2018) 209-220.

[19] C. Gogu, S.K. Bapanapalli, R.T. Haftka, B. Sankar, Rockets, Comparison of materials for an integrated thermal protection system for spacecraft reentry, J. Spacecraft Rockets 46 (2009) 501-513.

[20] D.C. Villanueva, R.L. Riche, G. Picard, R.T. Haftka, Dynamic design space partitioning for optimization of an integrated thermal protection system, AIAA/ASME/ ASCE/AHS/ASC Structures, Structural Dynamics \& Materials Conference, (2013).

[21] G. Xie, W. Qi, B. Sunden, W. Zhang, Thermomechanical optimization of lightweight thermal protection system under aerodynamic heating, Appl. Therm. Eng. 59 (2013) 425-434.

[22] S. Meng, Y. Qiang, W. Xie, C. Xu, J. Hua, Comparative study of structural efficiencies of typical thermal protection concepts, AIAA J. 55 (2017) 1-5.

[23] J. Fang, W. Yu, Y. Zheng, R. Kerans, Y.C. Ming, Analysis of reusable integrated thermal protection panel elements with various insulating core options, AIAA/ ASME/ASCE/AHS/SC Structures, Structural Dynamics, \& Materials Conference, (2006).

[24] Y. Ma, B. Xu, M. Chen, R. He, W. Wen, T. Cheng, D. Fang, Optimization design of built-up thermal protection system based on validation of corrugated core homogenization, Appl. Therm. Eng. 115 (2016) 491-500.

[25] S.Y. Zhao, C.X. Zhang, C.X. Zhang, W.J. Zhang, X. Lin, X.D. He, Y. Yao, Thermostructural optimization of integrated thermal protection panels with one-layer and two-layer corrugated cores based on simulated annealing algorithm, Struct. Multidiscip. Optim. 51 (2015) 479-494.

[26] K. Daryabeigi, S. Splinter, J. Knutson, Characterization of structurally integrated TPS for hypersonic vehicles, Fundamental Aeronautics Program Annual Meeting, October 7-9, 2008.

[27] Materials Research \& Design, Inc. Thermal protection for reentry and hypersonic systems. [EB/OL]. http://www.m-r-d.com/wpr/our-work/hypersonics-andreentry/.

[28] S. Meng, Y. Qiang, W. Xie, G. Han, S. Du, Structure redesign of the integrated thermal protection system and fuzzy performance evaluation, AIAA J. 54 (2016) $1-10$.

[29] Y. Qiang, S. Meng, W. Xie, J. Hua, C. Xu, S. Du, Effective mitigation of the thermal short and expansion mismatch effects of an integrated thermal protection system through topology optimization, Compos. B Eng. 118 (2017) 149-157.

[30] T. Ji, R. Zhang, B. Sunden, G. Xie, Investigation on thermal performance of high temperature multilayer insulations for hypersonic vehicles under aerodynamic heating condition, Appl. Therm. Eng. 70 (2014) 957-965.

[31] S.Y. Kee, Y. Munusamy, K. Ong, Review of solar water heaters incorporating solidliquid organic phase change materials as thermal storage, Appl. Therm. Eng. 131 (2018) 455-471.

[32] M. Amin, N. Putra, E.A. Kosasih, E. Prawiro, R.A. Luanto, T. Mahlia, Thermal properties of beeswax/graphene phase change material as energy storage for building applications, Appl. Therm. Eng. 112 (2017) 273-280.

[33] Q. Huang, X. Li, G. Zhang, J. Zhang, F. He, L. Yang, Experimental investigation of the thermal performance of heat pipe assisted phase change material for battery thermal management system, Appl. Therm. Eng. 141 (2018) 1092-1100.

[34] J. Coleto, M. Bausá, J. Maudes, T. Salmon, L. Martínez, A. Passaro, H. Ritter, Phase change materials and thermosensitive painting: Application on smart thermal 
protection systems, International Astronautical Congress (2006).

[35] G. Jiang, J. Huang, Y. Fu, C. Ming, M. Liu, Thermal optimization of composite phase change material/expanded graphite for Li-ion battery thermal management, Appl. Therm. Eng. 108 (2016) 1119-1125.

[36] H.K. Shin, M. Park, H.Y. Kim, S. Park, Thermal property and latent heat energy storage behavior of sodium acetate trihydrate composites containing expanded graphite and carboxymethyl cellulose for phase change materials, Appl. Therm. Eng. 75 (2015) 978-983.

[37] Y. Yuan, Z. Nan, W. Tao, X. Cao, Y. He, Fatty acids as phase change materials: A review, Renew. Sustain. Energy Rev. 29 (2014) 482-498.

[38] S. Zhang, W. Wu, S. Wang, Preparation, thermal properties and thermal reliability of a novel mid-temperature composite phase change material for energy conservation, Energy 130 (2017) 228-235.

[39] A. Sari, A. Karaipekli, Preparation, thermal properties and thermal reliability of palmitic acid/expanded graphite composite as form-stable PCM for thermal energy storage, Sol. Energy Mater. Sol. Cells 93 (2009) 571-576.

[40] K. Mills, Y. Su, Z. Li, R. Brooks, Equations for the calculation of the thermo-physical properties of stainless steel, ISIJ Int. 44 (2004) 1661-1668.

[41] M. Carosena, S. Boccardi, G. Carlomagno, Infrared Thermography in the Evaluation of Aerospace Composite Materials, Woodhead Publishing, 2017.

[42] S. Wu, T. Li, T. Yan, Y. Dai, R. Wang, High performance form-stable expanded graphite/stearic acid composite phase change material for modular thermal energy storage, Int. J. Heat Mass Transf. 102 (2016) 733-744.

[43] C. Chen, Z. Hua, X. Gao, X. Tao, Y. Fang, Z.J.E.C. Zhang, Numerical and experimental investigation on latent thermal energy storage system with spiral coil tube and paraffin/expanded graphite composite PCM, Energy Convers. Manage. 126 (2016) 889-897.

[44] S. Lorente, A. Bejan, J. Niu, M. Transfer, Constructal design of latent thermal energy storage with vertical spiral heaters, Int. J. Heat Mass Transf. 81 (2015) 283-288.

[45] Abaqus document, Version 6.12 Dassault Systemes Simulia Corp. 2012, Providence, RI, USA.

[46] R.D. Cook, H. Saunders, Concepts and Applications of Finite Element Analysis (second ed.), Wiley, 1974 